NBER WORKING PAPER SERIES

IRAS AND SAVINGS

Steven F. Venti

David A. Wise

Working Paper No. 1879

NATIONAL BUREAU OF ECONOMIC RESEARCH

1050 Massachusetts Avenue

Cambridge, MA 02138

April 1986

We are grateful for discussions with Axel Boersch-Supan, Angus Deaton, Mervyn King, Jim Poterba, and Jim Stock. The research was supported by grant number 84ASPE130A from the Department of Health and Human Services. The research reported here is part of the NBER's research program in Taxation and project in Taxation and Capital Formation. Any opinions expressed are those of the authors and not those of the National Bureau of Economic Research. 
NBER Working Paper \#1879

April 1986

IRAs and Saving

ABSTRACT

Increasing current Individual Retirement Account (IRA) limits would lead to substantial increases in tax-deferred saving according to evidence in the paper, based on the 1983 Survey of Consumer Finances. For example, the recent Treasury Plan would increase IRA contributions by about 30 percent. The primary focus of the paper, however, is the effect of limit increases on other saving. How much of the IRA increase would be offset by reduction in non-tax-deferred saving? The weight of the evidence suggests that very little of the increase would be offset by reduction in other financial assets. possibly 10 to 20 percent. The estimates suggest that 45 to 55 percent of the IRA increase would be funded by reduction in expenditure for other goods and services, and about 35 percent by reduced taxes. The analys is rests on a savings decision structure recognizing the constraint that the IRA limit places on the allocation of current income; it is a constrained optimization model with the IRA limit the principle constraint. The evidence also suggests substantial variation in saving behavior among segments of the population. In addition, it appears that IRAs do not serve as a substitute for private pension plans. Thus the legislative goal of disproportionately increasing retirement saving among persons without pension plans is apparently not being realized. But the more general goal of increasing general saving is.

Steven $F$. Venti

Department of Economics

Dartmouth College

Hanover, NH 03755
David A. Wise

J.F.K. School of Government

Harvard University

Cambridge, MA 02138 


\section{IRAS AND SAVING}

by

\section{Steven F. Venti and David A. Wise}

Individual retirement accounts (IRAs) were established in 1974 as part of the Employee Retirement Income Security Act to encourage employees not covered by private pension plans to save for retirement. The Economic Recovery Tax Act of 1981 extended the availability of IRAs to all employees and raised the contribution limit. The legislation emphasized the need to enhance the economic well-being of future retirees and the need to increase national saving. Now any employee with earnings above $\$ 2000$ can contribute $\$ 2000$ to an IRA account each year. An employed person and a non-working spouse can contribute a total of $\$ 2250$, while a married couple who are both working can contribute $\$ 2000$ each. Current tax proposals contemplate substantial increases in the limits. The tax on the principal and interest is deferred until money is withdrawn from the account. There is a penalty for withdrawal before age 59k, which is apparently intended to discourage the use of IRAs for non-retirement saving.

To determine whether IRA accounts serve as a substitute for private pension plans, it is important to know who contributes to IRAs. Whether they are an important form of saving for retirement depends on how much is contributed. In addition, the short-run tax cost of IRAs depends on their prevalence. These questions have been addressed by Venti and Wise [1985a] for the United States and by Wise [1984, 1985] for Canada. The central focus of this paper is the relationship between IRA contributions and other 
forms of saving. What is the net effect of IRA accounts on individual saving? In addressing this question, estimates of desired IRA contributions are also obtained, and these estimates can be compared with results based on other data sources.

Ideal data to answer this question would provide information on changes in all forms of assets over time. One could then compare annual IRA contributions with increases or decreases in other forms of saving. The set of questions that can be addressed directly with available data is limited, however. IRAs were only open to most employees beginning in 1982 and currently available data pertain only to that year. In addition, only limited information is available on changes in other asset holdings in 1982. Given the data limitations, the goal of the analysis presented in this paper is to estimate the effect that changes in the IRA contribution limit would have on other forms of saving, as well as on IRA contributions themselves. As explained below, other forms of saving probably are best thought of as liquid assets.

There are two central questions that arise in considering the effect of newly available IRAs on net saving: the first is the extent to which IRA contributions are made by withdrawing funds from other existing balances, and thus explicitly substituting one form of saving for another. Presumably such substitution would be made by taking funds from existing liquid asset balances, like other savings accounts. It is unlikely that in the short run, IRA contributions would be made by reducing non-liquid asset balances like housing. A related question, although possibly more subtle and difficult to answer empirically, is whether new saving would have been 
placed in other accounts were it not for the availability of IRAs, independent of existing balances.

Another question is the extent to which IRA contributions may ultimately serve as a substitute for non-liquid assets. In the long run individuals may contribute to IRAs instead of investing in housing, for example. This question is more difficult to address empirically, and no attempt is made to answer it here. Whether IRA contributions were substituted for other liquid assets in 1982 is the question that can be most directly addressed using the available data. But we believe that the estimates may also provide a reasonable indication of the trade-off between IRA contributions and liquid assets in the long run as well. The spirit of the paper is to distinguish direct evidence about which the results are likely to be relatively robust from questions about which the evidence is only indirect. An attempt is made to draw inferences based on the weight of the evidence. In short, given the available data and their limitations, what can be said about the effect of IRAs on net individual saving?

Background data on IRA contributions and other wealth holdings are presented in section I. The model used for estimation is developed in section II. Its key feature is constrained optimization, with the limit on IRA contributions the primary constraint. The principle goal is to obtain estimates of the effect of changes in IRA limits on other saving, as well as on IRA contributions themselves. The model addresses the allocation of current income. This approach has been chosen over a model of presumed lifetime saving behavior, although the allocation of current income could be thought of as the reduced form of a life cycle model. In addition, estimates 
of the allocation of current income based on age and other personal attributes allow inferences about life cycle saving behavior.

The results are presented in section III. The emphasis is on the sensitivity of the results to model specification and to the interpretation of a key variable, "savings and reserve funds." The most important results are presented in the form of simulations of the effect of proposed limit changes on IRA contributions and other saving. Some of the results developed here can be compared with evidence based on other data sources. Comparable evidence on IRA contributions for 1982 has been developed by Venti and Wise [1985], based on Current Population Survey data. The results of this paper are based on the 1983 survey of Consumer Finances (SCF), which presents information on IRAs in 1982. Section IV presents a summary of the findings and concluding discussion.

\section{Descriptive Statistics}

About 16 percent of wage earner families have IRA accounts, as shown in table 1.1 Almost no families with incomes under $\$ 10,000$ have them and only about 7 percent of families with incomes between $\$ 10,000$ and $\$ 20,000$. Somewhat more than half of those with incomes greater than $\$ 50,000$ contribute to IRAs. 2 The distribution of all contributors by income interval is as follows:

\footnotetext{
1self-employed persons have been excluded from the analysis.

${ }^{2}$ Numbers based on CPS data (Venti and Wise [1985]) indicate a higher proportion of wage earners with IRAs. While the CPS data are weighted to represent the employed population, the SCF data reported here are weighted to represent families with a wage earner.
} 
Income Interval

$0-10$

$10-20$

$20-30$

$30-40$

$40-50$

$50-100$

$100+$

\section{Percent of Contributors}

2

15

17

20

15

24

8

0lder persons are considerably more likely than younger ones to contribute, although the proportion drops at age 65 when a large proportion of employees retire. For example, among families in the $\$ 20,000$ to $\$ 30,000$ income interval, 36 percent of those 55 to 64 contributed but only 11 percent of those aged 25 to 34 .

The subsequent analysis will rely in part on responses to a question that asked: "Considering all of your savings and reserve funds, overal 1, did you put more money in or take more money out in 1982?"3 The precise interpretation that should be assigned the responses is unclear. In particular, it is not clear whether savings and reserve funds include or exclude IRA contributions. The analysis is conducted and the results are evaluated using both interpretations, although we believe it is most plausible to assume that IRAs are excluded. We presume that responses do not reflect non-liquid assets like housing. The proportion of families

\footnotetext{
${ }^{3}$ Three responses were possible: (1) Put more money in. (2) stayed the same. (3) Took more money out.
} 
Table 1. Proportion of families with IRA accounts,

by income and age a

\begin{tabular}{l|ccccccc}
\hline $\begin{array}{c}\text { Income } \\
\text { Interval } \\
\left(\$ 1000^{\prime} s\right)\end{array}$ & $<25$ & $25-34$ & $35-44$ & $45-54$ & $55-64$ & $65+$ & $A 11$ \\
\hline $0-10$ & .01 & .00 & .03 & .01 & .04 & .01 & .01 \\
$10-20$ & .04 & .04 & .04 & .09 & .20 & .04 & .07 \\
$20-30$ & .05 & .11 & .10 & .21 & .36 & .06 & .14 \\
$30-40$ & .15 & .25 & .14 & .34 & .43 & .19 & .25 \\
$40-50$ & .00 & .21 & .41 & .42 & .38 & .31 & .34 \\
$50-100$ & .00 & .33 & .51 & .53 & .75 & .36 & .51 \\
$100+$ & .49 & .66 & .79 & .65 & .58 & .65 \\
$\mathrm{~A} 11$ & .03 & .12 & .19 & .26 & .30 & .06 & .16 \\
\hline
\end{tabular}

a. The data are weighted to be representative of all families. The total sample size for this table is 3205 . 
Table 2. Proportion of families with increase in

"savings and reserve funds," by income and age ${ }^{a}$

\begin{tabular}{c|ccccccc}
\hline $\begin{array}{c}\text { Income } \\
\text { Interva } \\
\left(\$ 1000^{\prime} s\right)\end{array}$ & $<25$ & $25-34$ & $35-44$ & $45-54$ & $55-64$ & $65+$ & $A 11$ \\
\hline $0-10$ & .10 & .15 & .13 & .05 & .10 & .20 & .14 \\
$10-20$ & .33 & .23 & .19 & .12 & .32 & .35 & .26 \\
$20-30$ & .35 & .37 & .26 & .21 & .47 & .56 & .35 \\
$30-40$ & .31 & .46 & .40 & .47 & .41 & .58 & .44 \\
$40-50$ & .75 & .47 & .42 & .56 & .41 & .75 & .50 \\
$50-100$ & .00 & .48 & .56 & .54 & .57 & .71 & .56 \\
$100+$ & .58 & .56 & .53 & .47 & .54 & .65 & .54 \\
\hline 11 & .26 & .32 & .32 & .30 & .35 & .33 & .32 \\
\hline
\end{tabular}

a. The data are weighted to be representative of all families. The total sample size for this table is 3208 . 
indicating an increase in "savings and reserve funds" is shown in table 2 . Only 32 percent of respondents indicated an increase in 1982, while the remainder indicated a decrease or no change. 4 The proportion indicating an increase rises markedly with income, but shows little relationship to age.

A key consideration in our analysis is the relationship between IRA contributions and the change in "savings and reserve funds". Suppose IRA contributions were typically taken from "savings and reserve funds" balances. If savings and reserve funds include IRAs, there would be no change in overall savings and reserve funds. If the latter were interpreted to exclude IRAs, contributions to IRAs should be associated with a decline in savings and reserve funds. Apparently neither is true. Persons who contribute to IRAs are much more likely to indicate an increase than those who don't. The ratio of the proportion of IRA contributors with an increase in "savings and reserve funds" to the proportion of noncontributors with an increase is shown in table 3, by income and age. Overall, contributors are more than twice as likely as noncontributors to indicate an increase, although this number reflects in part different distributions of contributors and noncontributors by income and age. The average of the cell ratios is 1.77 .

Thus these numbers suggest that there are savers and non-savers and that savers save both through IRAs and through other forms; the positive relationship reflects an individual-specific effect. The subsequent analysis

\footnotetext{
${ }^{4}$ This evidence is consistent with the widespread perception that individual savings rates in the United States have been unusually low in recent years and that consumer debt has been increasing. See, for example, the New York Times, October 29, 1985; the Boston Globe, September 15 and November 22, 1985.
} 
Table 3. Proportion of IRA contributors with increase in "savings and reserve funds," $\div$ proportion of non-contributors with increase in "savings and reserve funds," by income and age a

\begin{tabular}{|c|c|c|c|c|c|c|c|}
\hline \multirow{2}{*}{$\begin{array}{l}\text { Income } \\
\text { Interval } \\
\text { (\$1000's) }\end{array}$} & \multicolumn{7}{|c|}{ Age Interval } \\
\hline & $<25$ & $25-34$ & $35-44$ & $45-54$ & $55-64$ & $65+$ & A11 \\
\hline $0-10$ & -- & -- & -- & -- & -- & -- & -- \\
\hline $10-20$ & -- & 1.83 & -- & -- & 1.60 & -- & 1.54 \\
\hline $20-30$ & -- & 1.61 & 2.41 & 2.16 & 1.41 & -- & 1.77 \\
\hline $30-40$ & -- & 1.45 & 1.92 & 1.48 & 2.38 & -- & 1.68 \\
\hline $40-50$ & -- & 1.60 & 1.56 & 1.24 & 3.10 & -- & 1.47 \\
\hline $50-100$ & -- & .96 & 1.65 & 1.41 & 1.62 & -- & 1.40 \\
\hline $100+$ & & -- & - & -- & .87 & -- & 2.19 \\
\hline A11 & -- & 1.78 & 2.37 & 2.22 & 2.00 & 1.86 & 2.10 \\
\hline
\end{tabular}

a. Not reported for cells in which there were fewer than 8 IRA contributors. 
provides support for an individual-specific savings effect, while also suggesting a substantial positive effect of IRAs on net individual saving.

To put IRA contributions in perspective and to help to interpret the analysis below, it is useful to have in mind the magnitude of individual wealth holdings. The median wealth of persons in the sample is $\$ 22,900$, excluding pensions and Social Security wealth. 5 Even among persons 55 to 64, the median is only $\$ 55,000$ (see table 4). Most of this wealth is nonliquid, the preponderance of which is housing. Consistent with other evidence (e.g., Hurd and Shoven [1985], Bernheim [1984], Diamond and Hausman [1984]), a large proportion of individuals have very little non-housing wealth; they save very little. Median liquid assets, excluding stocks and bonds, are shown in table 5, by income and age. The median for all families is $\$ 1,200$. For families earning $\$ 30,000$ to $\$ 40,000$ with a head 45 to 54 years it is only $\$ 4,600$. While most people have some liquid assets, only about 20 percent have financial assets in the form of stocks or bonds. 6 Thus it is clear that most people have not been accumulating financial assets at a rate close to the $\$ 2000$ per year that an IRA allows.

${ }^{5}$ The following breakdown of wealth is used throughout this paper: Liquid Assets: checking accounts, certificates of deposit, savings accounts, money market accounts, savings bonds Other Financial Assets: stocks, bonds, trusts IRAs and Keoghs: balances Dther Assets: value of home, other property and receivables Debt: mortgage and consumer debt

Total wealth is the sum of the first four categories minus debt. Weaith does not include the cash value of life insurance, the value of motor vehicles, and pension and social security wealth.

${ }^{6}$ The median for all financial assets including stocks and bonds is 1.3 , versus 1.2 when they are excluded. For more detail, see Venti and Wise [1985b]. 
Table 4. Median of wealth, by income and age a

\begin{tabular}{c|rrrrrrr}
\hline $\begin{array}{c}\text { Income } \\
\text { Interval } \\
(\$ 1000 ' s)\end{array}$ & $<25$ & $25-34$ & $35-44$ & $45-54$ & $55-64$ & $65+$ & $A 11$ \\
\hline $0-10$ & .3 & .0 & .1 & .1 & 1.5 & 10.0 & .5 \\
$10-20$ & .8 & 2.0 & 10.3 & 30.0 & 40.9 & 65.8 & 10.0 \\
$20-30$ & 2.5 & 13.8 & 31.6 & 44.6 & 90.2 & 125.5 & 28.3 \\
$30-40$ & 15.4 & 34.3 & 47.3 & 71.4 & 77.8 & 269.7 & 50.5 \\
$40-50$ & 10.9 & 40.3 & 74.6 & 90.5 & 114.4 & 219.0 & 80.6 \\
$50-100$ & 33.2 & 85.5 & 101.1 & 122.7 & 196.6 & 220.5 & 123.6 \\
$100+$ & - & 124.8 & 182.9 & 317.1 & 334.5 & 1308.7 & 279.0 \\
A11 & 0.6 & 5.9 & 35.6 & 47.1 & 55.0 & 40.1 & 22.9 \\
\hline
\end{tabular}

a. In $\$ 1000$ 's. The data are weighted to be representative of all families. The total sample size for this table is 2249 . 
Table 5 . Median of liquid assets, by income and age ${ }^{a}$

\begin{tabular}{l|rrrrrrr}
\hline $\begin{array}{c}\text { Income } \\
\text { Interval } \\
(\$ 1000 ' s)\end{array}$ & $<25$ & $25-34$ & $35-44$ & $45-54$ & $55-64$ & $65+$ & $A 11$ \\
\hline $0-10$ & .2 & .0 & .0 & .0 & .0 & .5 & .1 \\
$10-20$ & .4 & .3 & .5 & .9 & 3.5 & 16.2 & .7 \\
$20-30$ & .6 & 1.2 & 1.6 & 1.9 & 4.9 & 46.8 & 1.7 \\
$30-40$ & 1.0 & 2.9 & 2.4 & 4.6 & 3.6 & 107.0 & 3.5 \\
$40-50$ & 2.0 & 2.8 & 4.7 & 5.6 & 12.8 & 36.5 & 5.5 \\
$50-100$ & 16.4 & 5.7 & 13.8 & 8.7 & 22.1 & 37.8 & 12.8 \\
$100+$ & & 12.8 & 12.5 & 42.7 & 74.2 & 124.0 & 30.4 \\
A11 & .4 & .8 & 1.7 & 1.9 & 3.0 & 4.0 & 1.2 \\
\hline
\end{tabular}

a. In $\$ 1000^{\prime} s$. Stocks and bonds are excluded. The data are weighted to be representative of all families. The total sample size for this table is 2729 . 
Table 6. Median wealth of IRA contributors $\div$ median wealth of non-IRA contributors, by income and age ${ }^{a}$

\begin{tabular}{|c|c|c|c|c|c|c|c|}
\hline \multirow{2}{*}{$\begin{array}{c}\text { Income } \\
\text { Interval } \\
\text { (\$1000's) }\end{array}$} & \multicolumn{7}{|c|}{ Age Interval } \\
\hline & $<25$ & $25-34$ & $35-44$ & $45-54$ & $55-64$ & $65+$ & A11 \\
\hline $0-10$ & -- & -- & -- & -- & -- & -- & -- \\
\hline $10-20$ & -- & 6.05 & -- & -- & 1.95 & -- & 7.03 \\
\hline $20-30$ & -- & 1.81 & 1.61 & 1.18 & 1.23 & -- & 2.15 \\
\hline $30-40$ & -- & 1.55 & 1.74 & 1.14 & 1.11 & -- & 1.67 \\
\hline $40-50$ & -- & 1.58 & 1.77 & 1.62 & .73 & -- & 1.86 \\
\hline $50-100$ & -- & 1.66 & 1.17 & 1.03 & 1.03 & -- & 1.25 \\
\hline $100+$ & -- & -- & -- & -- & .25 & -- & 2.71 \\
\hline A11 & -- & 7.30 & 3.19 & 1.87 & 2.08 & 3.46 & 5.26 \\
\hline
\end{tabular}

a. Not reported for cells in which there were fewer than 8 IRA contributors. 
The median wealth of IRA contributors divided by the median wealth of noncontributors, by income and age, is shown in table 6 . Contributors have substantially higher wealth on average. The average of the cell ratios is 1.50 .7 The analys is below, however, indicates that after controlling for other variables, total wealth is in fact negatively related to IRA contributions. The results, including detail by liquid versus non-liquid wealth, suggest that the numbers in table 6 also reflect individual-specific saving effects; some people are savers, others are not.

In summary: the descriptive data confirm that low income persons are unlikely to contribute to IRAs. But they provide no direct evidence that IRA contributions are offset by reductions in other forms of saving; persons who contribute to IRAs are more likely than those who do not to indicate an overall increase in savings and reserve funds. The descriptive data, however, do not reveal whether savers save more because of the IRA option. The subsequent analysis is intended to shed light on this issue.

II. Allocation of Income: Individual Saving and IRA Constraints Given the limitations of the data, the goal is to develop a statistical model that will allow inferences based on the information that is available. The approach is to consider the allocation of current income in the spirit of expenditure studies, but with concentration on what is not spent for current consumption. The key feature of the approach is to incorporate the limit on tax-deferred saving in the estimation procedure

\footnotetext{
${ }^{7}$ Weighted by the number of IRA contributors.
} 
and then to infer from the parameter estimates how savings behavior would change if the limit were changed. To assure that estimated constrained and unconstrained behavior are internally consistent, the functional forms of the estimated equations are related through an underlying decision function. The model is intended to be "structural" with respect to changes in the IRA 1imit, although as explained below, not necessarily with respect to the individual variables that are used to estimate choice parameters of individuals. We begin with a simple example and then present the specifications used for estimation. For expository purposes, we also discuss first a specification that implies only a limited form of substitution between IRA and other saving. We then present a model that allows more flexible substitution and that incorporates the first as a special case.

\section{A. A Simple Example}

Suppose that current income $Y$ can be allocated to tax-deferred IRA saving $S_{1}$, to other forms of saving $S_{2}$, or to current uses, $Y-S_{1}-S_{2}$. Assume also that were there no limit on $s_{1}$, or if persons were not constrained by the limit, observed levels of $s_{1}$ and $s_{2}$ would be fit by the functions

$$
\begin{aligned}
& s_{1}=b_{1} Y, \text { and } \\
& s_{2}=b_{2} Y .
\end{aligned}
$$

For estimation, we need also to consider saving functions that are consistent with these, but for persons who are constrained by the 1 imit on $s_{1}$. These may be obtained by considering an underlying decision function that is consistent with observed saving decisions.

The saving allocations in (1) are in accordance with the decision 
function

$$
V=\left(Y-s_{1}-s_{2}\right)^{1-b_{1}-b_{2}} s_{1}^{b_{1}} s_{2}^{b_{2}}
$$

where $b_{1}$ and $b_{2}$ are parameters. Maximization of (2) with respect to $s_{1}$ and $s_{2}$ yields $(1)$. The presumption is that the $b^{\prime} s$ depend on measured personal attributes like age, income, wealth, education, marital status; unmeasured attributes that affect saving behavior in general; and unmeasured attributes like expected future liquidity needs or attitude toward risk that may affect the preferred allocation of income to $S_{1}$, versus $S_{2}$. This specification treats IRAs and other forms of saving as different "goods," thus emphasizing non-price differences between the two forms of saving. In particular, because of the early withdrawal penalty that makes IRAs less liquid than other saving, they may tend to be more narrowly targeted to retirement consumption; much of saving in other forms may be for different and more short term purposes. The "price" difference between the two forms of saving is brought out below. Following the decision function $(2)$, if $S_{1}$ cannot exceed the limit $L$, the saving functions are

$$
s_{1}= \begin{cases}b_{1} Y & \text { if } b_{1} Y<L, \\ L & \text { if } b_{1} Y \geqslant L,\end{cases}
$$

$$
s_{2}= \begin{cases}b_{2} Y & \text { if } b_{1} Y<L, \\ \frac{b_{2}}{1-b_{1}}(Y-L) & \text { if } b_{1} Y \geqslant L .\end{cases}
$$

The relationship between income and $s_{2}$ saving depends on whether the limit on the tax-deferred $S_{1}$ saving has been reached. In the subsequent discussion, 
we shall begin with a decision function, but it should be understood that it is chosen to be consistent with observed saving decisions. It is a construct that assures that constrained and unconstrained savings functions are consistent with each other.

It will be important to estimate the change in $S_{2}$ with a change in the limit $L$. In this case $d_{2} / d L=-b_{2} /\left(1-b_{1}\right)$, depending only on the $b$ 's. Thus to obtain good estimates of the effect of limit changes, it is necessary only to have good estimates of these parameters; not necessarily of the effect on the b's of the variables that will be used to estimate them. Figure 1 describes graphically the relationship between income and $s_{1}$ and $s_{2}$, with particular reference to the estimated specification described in section $B$ below.

\section{B. The Estimated Mode 1: A Special Case}

In practice, $s_{2}$ could be negative. "Desired" $s_{1}$ could also be negative, although not its observed value. Previous work by Venti and Wise [1985a] and by Wise [1985] indicates that IRA contributions alone can be described well by a Tobit specification with limits at zero and L. 8 In addition, the cost of one dollar of $\mathrm{s}_{1}$ in terms of current consumption is $(1-t)$, where $t$ is the marginal tax rate, whereas the cost of $s_{2}$ is 1 .

A decision function and implicit budget constraint that incorporates these characteristics is

$$
V=\left[Y-T-s_{1}(1-t)-s_{2}\right]^{1-b_{2}-b_{2}}\left[S_{1}-a_{1}\right]^{b_{1}}\left[s_{2}-a_{2}\right]^{b_{2}}
$$

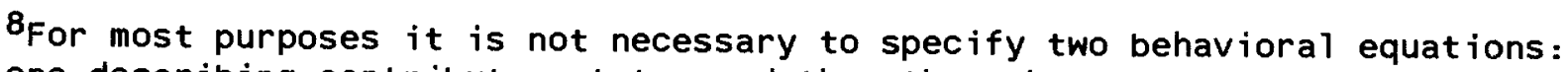
one describing contributor status and the other the amount. 
$-18-$

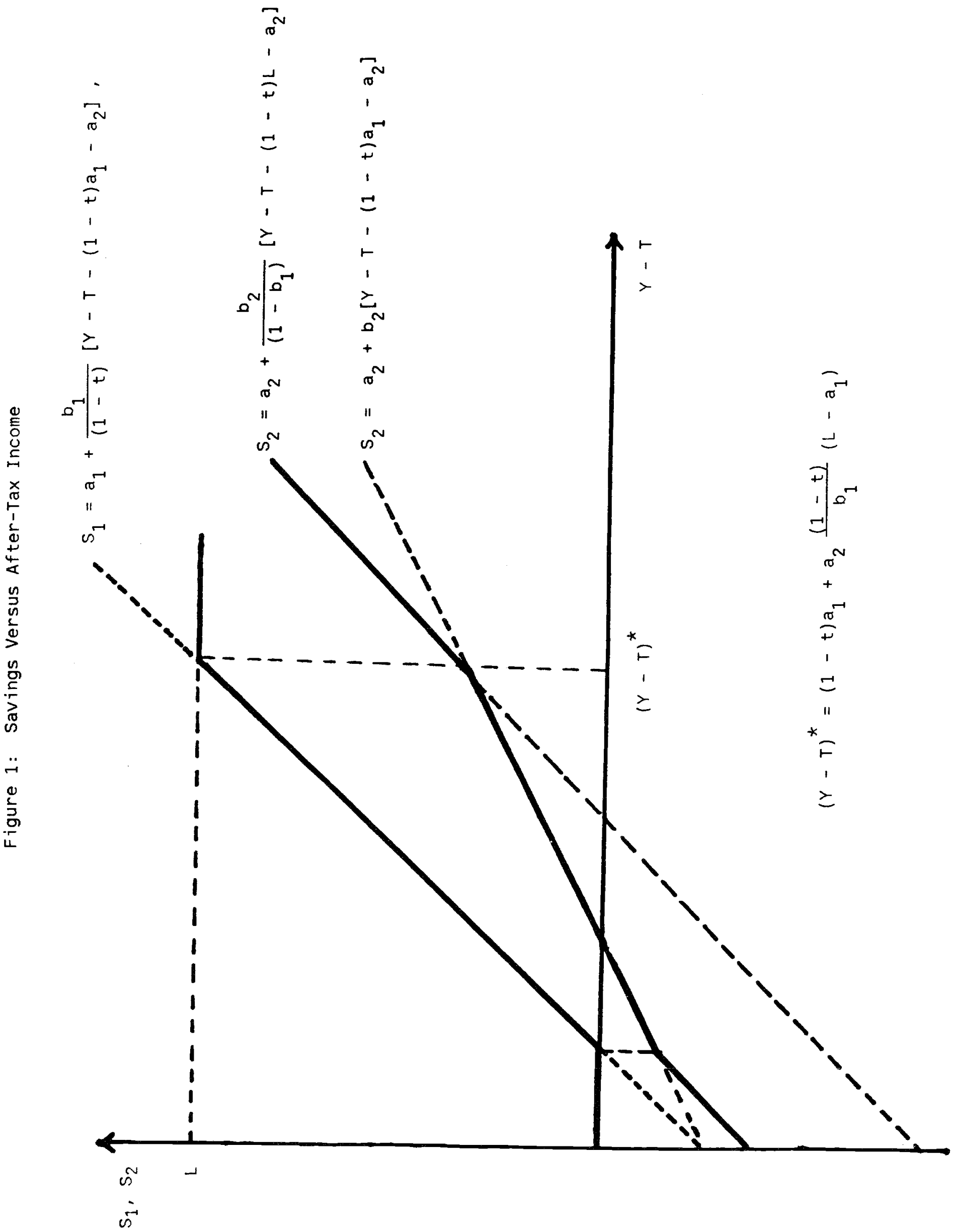


The presumption is that if both $s_{1}$ and $s_{2}$ were zero, current consumption would be $Y-T$, where $T$ is total taxes. This amount serves as the base case. If IRA contributions $s_{1}$ are made, taxes are reduced by $t s_{1} \cdot{ }^{9}$ In practice, "current consumption" includes some forms of saving like housing since the variable used to describe $s_{2}$ does not reflect all forms of non-IRA saving. 10

Consistent with (4), the "desired" level of tax-deferred saving $s_{1}$ is given by

$$
s_{1}=a_{1}+\frac{b_{1}}{(1-t)}\left[(Y-T)-(1-t) a_{1}-a_{2}\right],
$$

and the observed leve $1 s_{1}$ by

$$
s_{1}=\left\{\begin{array}{l}
0 \text { if } s_{1} \leqslant 0, \\
s_{1} \text { if } 0<s_{1}<L, \\
L \text { if } L \leqslant s_{1} .
\end{array}\right.
$$

Non-tax-deferred savings is given by

$$
s_{2}= \begin{cases}a_{2}+\frac{b_{2}}{1-b_{1}}\left[(Y-T)-a_{2}\right] & \text { if } s_{1}<0, \\ a_{2}+b_{2}\left[(Y-T)-a_{1}(1-t)-a_{2}\right] & \text { if } 0<s_{1}<L, \\ a_{2}+\frac{b_{2}}{1-b_{1}}\left[(Y-T)-L(1-t)-a_{2}\right] & \text { if } S_{1} \geqslant L .\end{cases}
$$

Stylized versions of the $s_{1}$ and $s_{2}$ functions are graphed in figure 1 , where $(Y-T)^{*}$ is the after-tax income level at which the limit $L$ on $S_{1}$ is

\footnotetext{
${ }^{9}$ In practice the marginal tax rate is not constant, but incorporating this non-linearity into the budget constraint would greatly increase the complexity of the analysis and we believe would not appreciably affect the results, given the small potential IRA contributions relative to income.

${ }^{10}$ While we use the decision function simply to provide consistent functional
} 
reached.

For expositional purposes, an advantage of the specification described above is that a closed form solution to the constrained saving function can be obtained from the decision function. This is not always the case. Indeed, as shown below, it is not true with the more general specification described in section $\mathrm{C}$ below. 11 General discussions of demand with "rationing" are presented in Deaton and Muellbauer [1981] and in Deaton [1981], with the discussion often in terms of indirect utility or expenditure functions. Deaton shows that closed form solutions to constrained demand functions can be obtained in some cases even when the utility function is not separable, the property that assures a closed form solution in the specification above.

The parameters $b_{1}$ and $b_{2}$ are specified as functions of individual attributes by

$$
\begin{aligned}
& b_{1}=\Phi\left[X B_{1}\right], \\
& b_{2}=\Phi\left[X B_{2}\right],
\end{aligned}
$$

where $X$ is a vector of individual characteristics and the B's are vectors of parameters to be estimated. The unit normal distribution function $\Phi$

forms for the constrained and unconstrained $s_{2}$ functions, there is some precedent for including asset (saving) balances in a true utility function. See for example Sidrauski [1967], Fischer [1979], Calvo [1979], Obstfeld [1984, 1985], and Poterba and Rotemberg [1986]. With $a_{1}$ and $a_{2}$ random, as described below, annual $\mathrm{S}_{1}$ and $\mathrm{S}_{2}$ flows could be thought of as proxies for balances.

${ }^{11}$ A similar situation characterizes the specification used by Hausman and Ruud [1984], for example, to describe family labor supply. Their specification yields unconstrained closed form solutions to the labor supply functions of the husband and the wife, consistent with an indirect utility function. But constrained functions analogous to ours are only defined implicitly. 
constrains $b_{1}$ and $b_{2}$ to be between 0 and 1.12

To allow for random preferences for saving among individuals, presumably reflecting unmeasured individual attributes, the parameters $a_{1}$ and $a_{2}$ are allowed to be stochastic, with a bivariate normal distribution

$$
\left[\begin{array}{l}
a_{1} \\
a_{2}
\end{array}\right] \sim \operatorname{BVN}\left(\left[\begin{array}{c}
\bar{a}_{1} \\
\bar{a}_{2}
\end{array}\right] ;\left[\begin{array}{cccc}
\sigma_{1}^{2} & \rho \sigma_{1} & \sigma_{2} \\
& & &
\end{array}\right]\right) \text {. }
$$

Large values of $a_{1}$ and $a_{2}$ indicate high desired $s_{1}$ and $s_{2}$ respectively; large $a_{1}$ means lower desired $s_{2}$ and large $a_{2}$ lower desired $s_{1} .13$ In addition, an alternative stochastic specification assumes that $a_{1}$ and $a_{2}$ are non-stochastic, but simple additive disturbance terms are added to the unconstrained $S_{1}$ and $S_{2}$ equations. Details of the stochastic structure under both specifications are presented in Venti and wise [1985b]. An important parameter is the correlation between the disturbance terms in $s_{1}$ and $\mathrm{S}_{2}$. This correlation contributes to inference about the extent to which observed saving behavior results from unmeasured individual-specific effects or the extent to which saving in one form is offset by saving in another. The possible outcomes and associated probability statements are listed below, under the two interpretations of "savings and reserve funds",

${ }^{12}$ Thus, for example, $b_{1}=\int_{-\infty}^{X B} 1 v d v$, where $v$ is a standard normal variable. In practice, very few predicted $b_{1}$ or $b_{2}$ values are below zero, if the constraint
is not imposed.

$$
\begin{aligned}
13 \partial S_{1} / \partial a_{1} & =1-b_{1}, \partial s_{2} / \partial a_{2}=1-b_{2}, \\
\partial S_{1} / \partial a_{2} & =-b_{1} /(1-t), \quad \partial s_{2} / \partial a_{1}=-b_{2}(1-t) .
\end{aligned}
$$


denoted by $s$. If $s$ includes IRAs, $s=s_{1}+s_{2}$; if it does not, $s=s_{2}$.

Outcomes and Associated Probabilites

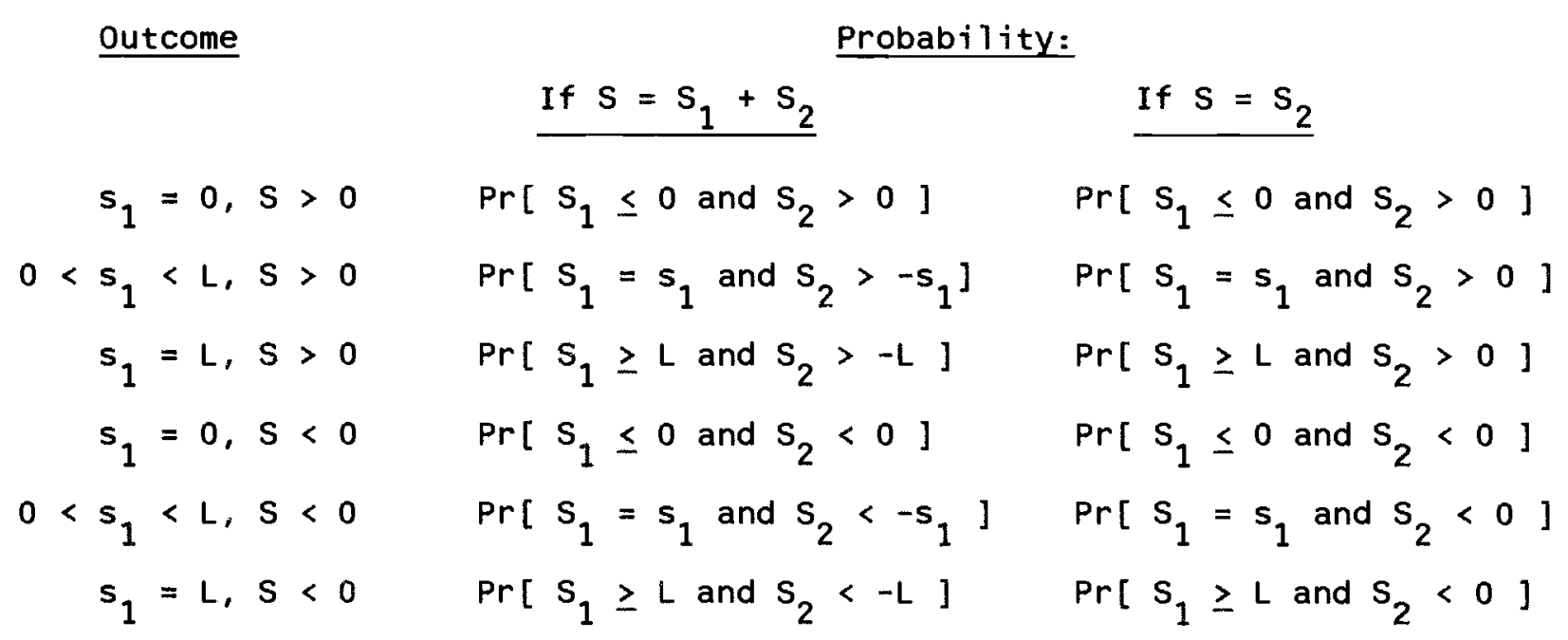

The latter interpretation is we believe the most likely to reflect the respondent's intent. Most of the discussion and reported simulations are based on this assumption. Nonetheless, we shall present some estimates based on the $S=S_{1}+S_{2}$ interpretation. This interpretation should provide the most stable estimates.14 We show that estimates based on this interpretation are rather insensitive to important assumptions. Estimates are obtained by maximum likelihood.

Implicit in the functional form described above is an "independence" assumption that restricts the implied substitution between $S_{1}$ and $S_{2}$ on the one hand and current consumption on the other. Consider the allocation of a marginal dollar of current income before and after the limit on $\mathrm{S}_{1}$ has been reached. The marginai shares allocated to $s_{1}, s_{2}$, and consumption are:

${ }^{14}$ To determine the magnitude of $S_{2}$, not just its sign, it is necessary to identify its residual variance. 2In many situations similar to this, identification of both $\sigma_{2}$ and $\sigma_{1}$ would not be possible given only qualitative 
Unconstrained $^{15}$

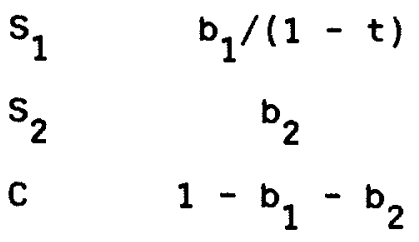

Constrained

0

$$
\begin{gathered}
b_{2} /\left(1-b_{1}\right) \\
\left(1-b_{1}-b_{2}\right) /\left(1-b_{1}\right)
\end{gathered}
$$

Thus the ratio of the marginal share that goes to $S_{2}$ versus the share that goes to consumption, $b_{2} /\left(1-b_{1}-b_{2}\right)$, is independent of whether the limit on $S_{1}$ has been reached. One might expect, however, that this ratio would increase after the limit is reached if there is greater substitution between $s_{1}$ and $s_{2}$ than between $e i t h e r$ of these and consumption.

The importance of this property is what it implies about the effect of an increase in the tax-deferred limit $L$ on non-tax-deferred saving $\mathrm{S}_{2}$. Only persons at the limit will be affected by increasing it. For these people, $\mathrm{dS}_{1} / \mathrm{dL}=1$. The amount that is taken from non-tax-deferred saving to fund the dollar increase in $s_{1}$ is $d S_{2} / d L=-(1-t) b_{2} /\left(1-b_{1}\right)$, for those who are at the limit. 16 The amount from consumption is $-(1-t)\left(1-b_{1}-b_{2}\right) /\left(1-b_{1}\right)$. Thus the model implies a proportionate reduction in $S_{2}$ and $C$ in accordance with the unconstrained shares. Therefore results based on a functional form that allows more flexible substitution

information on $S_{2}$, its sign. In this case, however, identification is in principle provided by three features of the model: (1) the functional form itself; (2) the limit $L$ on $S_{1}$; and (3) by direct information on the value of $\mathrm{S}_{2}$ in addition to its sign, if "savings and reserve funds" is interpreted to include IRAs. For more detail, see Venti and Wise [1985b]. ${ }^{15} \mathrm{~A}$ dollar of current after-tax income allocated to $s_{1}$ yields $s_{1} /(1-t)$ in taxdeferred saving.

${ }^{16}$ This effect can be seen from figure 1 . The effect of changing the limit is to shift downward the function $S_{2}$ described by the steeper sloped segment of the $S_{2}$ function and the dashed extension of it. 
between $S_{1}$ and $S_{2}$ are also obtained.

\section{Relaxing the Independence Assumption}

To relax the restrictive substitution implications of the specification above, suppose that preferred allocations of current income are in accordance with the function

(9) $V=\left[Y-T-P_{1} S_{1}-P_{2} S_{2}\right]^{1-\beta}\left\{\left[\alpha\left(s_{1}-a_{1}\right)^{k}+(1-\alpha)\left(s_{2}-a_{2}\right)^{k}\right]^{\frac{1}{k}}\right\}^{\beta}$, where the left-hand term in brackets incorporates the budget constraint. The cost of $S_{1}$ in terms of current consumption is $P_{1}$ and the cost of $S_{2}$ is $P_{2}$. This function has a tree structure with one branch consumption and the other saving. The two branches are combined in a Cobb-Douglas manner with parameter B. The two forms of saving are combined in a C.E.S. subfunction to form the saving branch. The parameter $\alpha$ indicates the relative "preference" for $s_{1}$ versus $s_{2}$. If they were treated as equivalent, $\alpha$ would equal .5 .17 The elasticity of substitution between $s_{1}$ and $s_{2}$ is $1 /(1-k) .18$

The limiting case of $(1)$ as $k$ goes to zero is given by

$$
V=\left[\gamma-T-s_{1}(1-t)-s_{2}\right]^{1-\beta}\left[s_{1}-a_{1}\right]^{\alpha \beta}\left[s_{2}-a_{2}\right]^{(1-\alpha) \beta},
$$

with $P_{1}=1-t$ and $P_{2}=1$. The unrestricted "desired" levels of $S_{1}$ and $S_{2}$ are given by ${ }^{17}$ In this case, with $P_{1}=P_{2}$, desired $S_{1}$ would equal desired $S_{2}$, as can be seen
from equation (14) below.

${ }^{18}$ This specification is thus a slight variant of the "S-branch" utility tree of Brown and Heien [1972]. See also Blackorby, Boyce, and Russe 11 [1978]. 


$$
\begin{aligned}
& S_{1}=a_{1}+\frac{\alpha}{(1-t)} \beta\left[Y-T-(1-t) a_{1}-a_{2}\right], \\
& S_{2}=a_{2}+(1-\alpha) \beta\left[Y-T-(1-t) a_{1}-a_{2}\right] .
\end{aligned}
$$

The function (10) is the same as the preference function (4) above and yields the same constrained savings functions as those in equations (5) and (6), but with $b_{1}=\alpha \beta$ and $b_{2}=(1-\alpha) \beta$.

Because the parameters $\alpha$ and $\beta$ have informative interpretations, we shall estimate them as functions of $x$, as an alternative to estimation of $b_{1}$ and $b_{2}$. Although if $b_{1}, b_{2}, \alpha$, and $\beta$ were the same for all persons in the sample -- not functions of attributes $x$-- the equalities would hold, they will not necessarily hold when each is estimated as a function of $x$. For example, the mean over $x$ of $\hat{b}_{1}=\Phi\left[X \hat{B}_{1}\right]$ will not equal the mean over $x$ of $\hat{\alpha} \cdot \hat{\beta}$. Analagous to the parameterization of $b_{1}$ and $b_{2}$, we estimate $\alpha$ and $\beta$ as

$$
\begin{aligned}
& \alpha=\Phi[X A], \\
& \beta=\Phi[X B],
\end{aligned}
$$

where $A$ and $B$ are vectors of parameters to be estimated.

With this parameterization, it is convenient to think of $\beta$ as the marginal after-tax dollar devoted to saving $\left(S_{1}\right.$ and $\left.S_{2}\right)$ and $\alpha$ as the proportion of a saved dollar devoted to $s_{1}$. Define $\gamma_{1}=\alpha /(1-t)$. It is the amount of tax-deferred $s_{1}$ obtained for the proportion $\alpha$, and $\gamma_{2}=1-\gamma_{1}(1-t)=1-\alpha$ is the proportion devoted to non-tax-deferred $s_{2} \cdot 19$ If $k \neq 0$, it is informative first to describe the savings functions in

${ }^{19}$ The $\alpha, \beta$ parameterization essentially al lows interactions between the $x$ variables and thus the difference in the two parameterizations is more than just interpretation. Setting $\alpha=b_{1} /\left(b_{1}+b_{2}\right), \beta=b_{1}+b_{2}$, and parameterizing $b_{1}$ and $b_{2}$ would yield results the same as the section $B$ 
terms of both $P_{1}$ and $P_{2}$. In this case, the unconstrained desired levels of $\mathrm{s}_{1}$ and $\mathrm{s}_{2}$ are given by

$$
S_{1}=a_{1}+\gamma_{1} \beta\left(\gamma-T-P_{1} a_{1}-P_{2} a_{2}\right)
$$

$$
S_{2}=a_{2}+\gamma_{2} \beta\left(Y-T-P_{1} a_{1}-P_{2} a_{2}\right)
$$

From the constraint $\gamma_{1} P_{1}+\gamma_{2} P_{2}=1, \gamma_{2}=\left(1-\gamma_{1} P_{1}\right) / P_{2}$. The distribution factor $\gamma_{1}$ is given by

$$
\gamma_{1}=\frac{\left(P_{1} / \alpha\right)^{\frac{1}{k-1}}}{P_{1}\left(P_{1} / \alpha\right)^{\frac{1}{k-1}}+P_{2}\left[P_{2} /(1-\alpha)\right]^{\frac{1}{k-1}}}
$$

With $P_{2}=1$ and $\gamma_{2}=1-\gamma_{1} P_{1}, \gamma_{1}$ can be written as

$$
\gamma_{1}=\frac{P_{1}^{\frac{1}{k-1}}}{P_{1} \cdot P_{1}^{\frac{1}{k-1}}+(\alpha /(1-\alpha))^{\frac{1}{k-1}}}
$$

If $k=0$, this expression reduces to $\alpha / P_{1}=\alpha /(1-t)$ as in equation (11). If the $s_{1}$ constraint is binding so that $s_{1}=L, S_{2}$ is defined only implicitly, by the relationship

$$
\frac{P_{2}(1-\beta)\left[\alpha\left(L-a_{1}\right)^{k}+(1-\alpha)\left(S_{2}-a_{2}\right)^{k}\right]}{(1-\alpha)\left(S_{2}-a_{2}\right)^{k-1}}=\left(Y-T-P_{1} L-P_{2} S_{2}\right)
$$

obtained by maximizing (9) with respect to $S_{2}$, with $S_{1}=L$. This function must be evaluated at each iteration of the maximum likelihood estimation routine.

specification. 
We have not attempted to do this with random $a_{1}$ and $a_{2}$. Only the additive disturbance specification has been used in this case. Estimates based on the restricted specification described in section $B$, however, lead us to believe that the results are not very sensitive to which of these stochastic specifications is used. 20

\section{Results}

\section{A. Data}

The estimates are based on the 1983 survey of Consumer Finances. The Survey provides detailed information on asset balances of all kinds, as well as on income and other personal attributes. From data on IRA balances it is possible to infer 1982 contributions, as explained in appendix $A$. Unfortunately the data do not include changes in other asset balances in 1982, as emphasized above. The absence of this data has led us to concentrate on information contained in the change in "savings and reserve funds" question.

Estimation is based on 1068 observations. Families were deleted from the original sample if they were ineligible for an IRA (self-employed or not working). Nonresponse reduced the sample further. The data most often missing were self-reported marginal tax rates and the series of responses required to calculate housing equity. The variable means in the estimation sample (Appendix Table 1) are very close to the means for all of

${ }^{20}$ Similar evidence for the $k=0$ case is presented in Venti and Wise [1985b], but with $\alpha$ and $\beta$, instead of $b_{1}$ and $b_{2}$, parameterized. 
those surveyed, however. 21 Estimates based on a larger sample using predicted marginal tax rates are not appreciably different from those reported below based on self-reported rates.

\section{B. Parameter Estimates}

As emphasized above, the main concern is to obtain "reliable" estimates of $b_{1}$ and $b_{2}$ (or of $\alpha$ and $\beta$ ); they are the principle determinants of the effect of a change in L on IRA and non-IRA saving. While the effect of the variables $x$ on the $b^{\prime} s$ is of interest, it is not necessary to obtain unbiased estimates of these effects to estimate the effect of changing $L$. The model is intended to be structural with respect to $L$, not necessarily with respect to the effects of the variables $X$ that determine the $b^{\prime} s .22$ Given the limit $L$, the parameters $a_{1}$ and $a_{2}$, and the parameters $b_{1}$ and $b_{2}, s_{1}$ and $S_{2}$ savings are given by the functions like those graphed in figure 1 . Their amounts may be calculated given after-tax income, $Y-T$. If the limit is increased by $\Delta L$, the constrained $S_{2}$ function is shifted downward by $-\left[(1-t) b_{2} /\left(1-b_{1}\right)\right] \cdot \Delta L$, using equation $(6)$, and its intersection (the kink point in figure 1) with the unconstrained function is shifted outward. Given the new limit, new $s_{1}$ and $s_{2}$ values may be calculated. The effect of changing the limit depends only on $b_{1}$ and $b_{2}$. Thus in reporting the results we

21 For example, mean wealth in the estimation sample is $\$ 59,781$ and it is $\$ 59,090$ in the total sample, mean age is 37.7 versus 39.4 , mean education is 13.4 versus 12.2, and the mean self-reported marginal tax rate is 0.25 versus 0.27 .

22 Using the regression analogy, it is equivalent to obtaining an unbiased estimate of $E(Y \mid X)$, where $Y=X b+\epsilon$, rather than unbiased estimates of each component of $b$. 
emphasize the sensitivity of the estimated values of $b_{1}$ and $b_{2}$ to model specification. To simulate the average effect of a limit change, random values of $a_{1}$ and $a_{2}$ are selected from a bivariate normal distribution using the estimated means and covariance terms. (The alternative specification assumes additive disturbances on the $S_{1}$ and $S_{2}$ equations, also with a bivariate normal distribution.) 23

We begin with estimates based on the limited substitution model with $b_{1}$ and $b_{2}$ parameterized (equations 5 and 6 ). Based on this specification we shall first consider a base case with $S=s_{2}$. We then discuss variants of this specification, some under the assumption that $s=s_{1}+s_{2}$. The estimates with $s=s_{1}+s_{2}$ should in principle be the most stable. We show in particular that the estimated values of $\sigma_{1}$ and $\sigma_{2}$ are very close and that the hypothesis that $\sigma_{1}=\sigma_{2}$ cannot be rejected. This is a potentially important restriction that has been imposed under the assumption that $s=s_{2}$.

These latter estimates may be compared with those obtained with $k=0$ but with $\alpha$ and $\beta$, instead of $b_{1}$ and $b_{2}$, parameterized. To provide a summary measure that allows comparison across the specifications, we present estimated values of $s_{1}$ and $s_{2}$ saving out of the marginal dollar of after-tax income, defined by

$$
\begin{aligned}
& \delta_{1}=\frac{b_{1}}{(1-t)}=\frac{\alpha}{(1-t)} \beta, \text { and } \\
& \delta_{2}=b_{2}=(1-\alpha) \beta,
\end{aligned}
$$

where the equalities hold only if $b_{1}$ and $b_{2}, \alpha$ and $\beta$ are not parameterized. Finally, estimates with $k$ set at .65 are presented. In practice,

${ }^{23} \mathrm{~A}$ potentially important assumption is the presumed distribution of the random terms. The results below show that the model fits the observed data well by income interval and this provides some support for the distributional 
widely varying values of $k$ cannot be distinguished by the data. 24 Withinsample predictions are essentially the same. Nonetheless the predicted effects of limit changes do depend on the assumed substitution behavior under which the data were generated. Thus we set $k$ at a rather high leve 1 and obtain estimates for the other parameters. Indications of model fit, simulation results, and the sensitivity of the simulations to model specification follow.

1. Limited Substitution, $b_{1}$ and $b_{2}$ Parameterized a. The Base Specification

Parameter estimates obtained under the assumption that $s=s_{2}$ are shown in Table 7 . The correlation between the random preference parameters $a_{1}$ and $a_{2}$ is .47 (with a standard of error of .06). The implied correlation between the $S_{1}$ and $s_{2}$ disturbance terms is .16, evaluated at the mean of the data. Although the correlation is small, it is consistent with an individualspecific savings effect (presumably due to unmeasured individual attributes) that affects both IRA and other saving in the same direction. It does not provide support for the possibility that persons who save more in one form

assumptions. A better test would be to use the model to predict the effect of a limit change. While this is not possible for the United States, such predictions have been made for Canadian tax-deferred saving contributions using a specification similar to the one used here for IRA contributions. The model estimated using data from one year predicted very accurately the contributions in a later year with a 60 percent lower contribution 1 imit, and vice-versa. See Wise [1984, 1985]. The results are also summarized in Venti and Wise [1985a].

${ }^{24}$ Similar findings are reported by Mundlak [1975] and by Griliches and Ringstad [1971] with respect to production data. In our case, the likelihood function is very flat around $k=0$. 
Table 7. Parameter estimates with $b_{1}$ and $b_{2}$ parameterized and $s=s_{2}$.

\begin{tabular}{|c|c|c|c|c|c|}
\hline \multirow{2}{*}{$\frac{\text { Variable }}{\text { Origin Parameters: }}$} & \multicolumn{5}{|c|}{ Estimate (Asymptotic Standard Error) } \\
\hline & \\
\hline Mean of $a_{1}$ & \multicolumn{5}{|c|}{$15.90(2.09)$} \\
\hline Mean of $a_{2}$ & \multicolumn{5}{|c|}{$4.58(.97)$} \\
\hline S.D. of $a_{1}$ & \multicolumn{5}{|c|}{$8.89(1.10)$} \\
\hline S.D. of $a_{2}$ & \multicolumn{5}{|c|}{$8.89(--)$} \\
\hline Correlation of $a_{1}, a_{2}$ & \multicolumn{5}{|c|}{$.47(.06)$} \\
\hline S.D. of $S_{1}$ (at mean) & \multicolumn{5}{|c|}{6.66} \\
\hline S.D. of $S_{2}$ (at mean) & \multicolumn{5}{|c|}{7.92} \\
\hline Correlation of $s_{1}, s_{2}$ & \multicolumn{5}{|c|}{.16} \\
\hline Determinants of $b_{1}$ and $b_{2}$ : & \multicolumn{3}{|l|}{$b_{1}$} & \multicolumn{2}{|c|}{$b_{2}$} \\
\hline Income $\left(\$ 1000^{\prime} s\right)$ & \multicolumn{3}{|c|}{$-.00501(.00070)$} & \multicolumn{2}{|c|}{$-.01042(.00242)$} \\
\hline Age (years) & \multicolumn{3}{|c|}{$.0112 \quad(.0019)$} & \multicolumn{2}{|c|}{$.0002 \quad(.0044)$} \\
\hline Total wealth (\$1000's) & \multicolumn{3}{|l|}{---} & \multicolumn{2}{|l|}{---} \\
\hline Non-liquid & \multicolumn{3}{|c|}{$-.00024(.00010)$} & -.00024 & $(.00048)$ \\
\hline Liquid & \multicolumn{3}{|c|}{$.00073(.00048)$} & .01131 & $(.00322)$ \\
\hline Private pension $(0,1)$ & \multicolumn{3}{|c|}{$-.0140 \quad(.0401)$} & .9006 & $(.3703)$ \\
\hline Education (years) & \multicolumn{3}{|c|}{$.0248 \quad(.0080)$} & .0366 & $(.0228)$ \\
\hline Unmarried woman & \multicolumn{3}{|l|}{.0831} & .1703 & $(.1413)$ \\
\hline Unmarried man & \multicolumn{3}{|l|}{.0486} & .2667 & $(.1019)$ \\
\hline Constant & -1.5752 & $(.2043)$ & & -2.3675 & $(.6762)$ \\
\hline Predicted $b_{1}$ and $b_{2}$ : & $\mathrm{b}_{1}$ & & & $\mathrm{~b}_{2}$ & \\
\hline Mean & .174 & & & .102 & \\
\hline S.D. & .037 & & & .072 & \\
\hline Min & .012 & & & .000 & \\
\hline $\operatorname{Max}$ & .310 & & & .820 & \\
\hline Predicted $\delta_{1}$ and $\delta_{2}$ & $\delta_{1}$ & & & $\delta_{2}$ & \\
\hline Mean & .247 & & & .102 & \\
\hline S.D. & .162 & & & .072 & \\
\hline Min & .012 & & & .000 & \\
\hline $\operatorname{Max}$ & 4.448 & & & .820 & \\
\hline $\mathbf{F}$ & & -13 & & & \\
\hline
\end{tabular}


tend to save less in the other. This substitution hypothesis would be consistent with a negative correlation.

The estimated coefficients on the wealth variables also seem consistent with an individual-specific savings effect. Liquid assets, which are likely to be the most readily transferred to IRA accounts are positively related to IRAs, but they are also positively related to other saving. Indeed the relationship to the $S_{2}$ saving is much greater than the relationship to IRAs. A $\$ 1,000$ increase in liquid assets is associated with a $\$ 45$ increase in $S_{2}$, but only a $\$ 5$ increase in $S_{1}$. Parameterization in terms of $\alpha$ and $\beta$ shows a positive relationship of liquid assets to total saving in the two forms but a negative relationship to the proportion of the total devoted to IRAs, as shown in table 8 below. Non-liquid assets are negatively related to both $S_{1}$ and $S_{2}$ saving. Parameterization of $\alpha$ and $\beta$ shows that non-1iquid wealth is negatively related to total saving in these forms, but is positively related to the proportion devoted to IRAs. (As shown in appendix table 4 , total wealth is negatively related to total saving in the $S_{1}$ and $S_{2}$ forms, and is unrelated to the allocation to $S_{1}$ versus $S_{2} \cdot$ ) Thus this evidence also seems to support individual-specific saving preferences; some persons are savers and others not, some save in liquid and others in less liquid forms. But the evidence does not provide much support for the possibility that IRA funds were typically withdrawn from other liquid asset balances. 25

It is important to keep in mind that in this specification, cumulated assets serve as a measure of individual-specific savings effects. They are

${ }^{25}$ It is not possible to reach strong conclusions based on this evidence because the asset balances are reported after an IRA contribution and because it is not clear what the relationship should be if liquid assets, say, are larger than the IRA limit. But if liquid assets were relatively large at the end of the period one might suppose that they were large when the IRA decision was 
not intended to serve as exogenous determinants of the b's; in this sense they would be endogenous. But their relationship to the b's also provides us with information about the hypothesis that IRA contributions are simply taken from other saving balances.

The mean estimated $b_{1}$ and $b_{2}$ parameters, .174 and .102 respectively, also suggest a strong preference for IRA versus other saving. At the margin, 17 cents of an additional dollar of after-tax income would go to IRAs -yielding about 25 cents in IRA saving -- and about 10 cents would go to $\mathrm{S}_{2}$ saving.

It is tempting to explain the difference between $b_{1}$ and $b_{2}$ by the difference in the return to tax-deferred versus non-tax-deferred saving. The revealed preference for IRAs is distinct from the lower price of tax-deferred saving in terms of current consumption, which through the current year budget constraint of our model serves to increase the amount of IRA saving, given $b_{1}$ and $b_{2}$. For example, suppose that $r$ is the interest rate, $t$ ' is the marginal tax rate during the time that funds are in an IRA account, $t$ is the rate when funds are withdrawn, and the contribution is made at age $j$ ' and withdrawn at age $j$. A dollar invested in an IRA yields $1 \cdot(1-t) e^{r\left(j-j^{\prime}\right)} \cdot[1-p(j)]$, where $p(j)$ is a penalty for early withdrawa?. The penalty is 0 if $j>59 \frac{1}{2}$ and .1 if $j<59 \frac{1}{2}$. A dollar of non-tax-deferred saving yields $\left(1-t^{\prime}\right) e^{r\left(1-t^{\prime}\right)\left(j-j^{\prime}\right)}$. Thus the ratio of the tax- to nontax-deferred yields is $\left[(1-t) /\left(1-t^{\prime}\right)\right] e^{r t\left(j-j^{\prime}\right)} \cdot[1-p(j)]$. If $t=t^{\prime}$

made. One might also suppose that the larger the liquid asset balances, the easier it would be to forego liquidity and to put money in an IRA. 
and $j>591 / 2$, it is simply $e^{r t\left(j-j^{\prime}\right)}$. Thus because of the tax free compounding of interest in IRA accounts, as well as the possible difference between pre- and post-retirement tax rates, persons in higher marginal tax brackets should have a greater incentive to save through IRAs. 26

The penalty for early withdrawal makes the IRA less liquid and thus may detract from the desirability of IRAs, however. 27 But the liquidity consideration should be less important for people with higher marginal tax rates. Taking account of the penalty for early withdrawal, the tabulation below shows the number of years that funds must be left in an IRA account for the return to exceed the non-tax-deferred return.

${ }^{26}$ It is also informative to consider the cost, in terms of current consumption, of providing retirement income. Suppose, thinking in a manner roughiy consistent with statements of some pension planners, an individual wants to accumulate a given retirement fund by age $j>59 \frac{1}{2}$. If the amount accumulated through $S_{1}$ saving is to be equivalent to that accumulated through $s_{2}$ saving, $s_{1}(1-t) e^{r\left(j-j^{\prime}\right)}=s_{2}\left(1-t^{\prime}\right) e^{r\left(1-t^{\prime}\right)\left(j-j^{\prime}\right)}$. The amount of required $s_{2}$ relative to $s_{1}$ would be $s_{2} / s_{1}=\left[(1-t) /\left(1-t^{\prime}\right)\right] e^{r t^{\prime}\left(j-j^{\prime}\right)}$. The cost in terms of current consumption is given by $\left(s_{2} / s_{1}\right)=\left[c_{2} / c_{1}\left(1-t^{\prime}\right)\right]$, where $c$ represents current consumption cost. Thus

$\left.c_{2} / c_{1}=[1-t) /\left(1-t^{\prime}\right)^{2}\right] e^{r t^{\prime}\left(j-j^{\prime}\right)}$. If $t=t^{\prime}$, $c_{2} / c_{1}=\left[1 /\left(1-t^{\prime}\right)\right] e^{r t^{\prime}\left(j-j^{\prime}\right)}$. This is of course another way of emphasizing the IRA advantage. But it also suggests that the income effect created by the lower IRA cost could in theory lead to greater consumption, although the parameter estimates themselves, together with the simulations presented below, are inconsistent with this conceptual possibility.

27 We say may because one of us finds the non-liquid aspect of the IRA a positive attribute. So much for "rational" behavior. 


\begin{tabular}{cccccc} 
& \multicolumn{5}{c}{ Margina Tax Rate } \\
Interest Rate & $\underline{10 \%}$ & $\underline{20 \%}$ & $\underline{30 \%}$ & $\underline{40 \%}$ & $\underline{50 \%}$ \\
$2 \%$ & 60.0 & 34.0 & 26.1 & 23.2 & 22.6 \\
$6 \%$ & 20.8 & 11.7 & 9.0 & 8.0 & 7.8 \\
$10 \%$ & 12.9 & 7.3 & 5.6 & 4.9 & 4.8 \\
$14 \%$ & 9.5 & 5.4 & 4.1 & 3.6 & 3.5 \\
$18 \%$ & 7.7 & 4.3 & 3.3 & 2.9 & 2.8
\end{tabular}

Thus it is clear that both the interest rate and the marginal tax rate should have a substantial effect on the desirability of IRAs to the extent that short-term liquidity is an important consideration.

We are, however, unable to demonstrate convincingly an increasing preference for IRAs with increasing marginal tax rates. The coefficient on the marginal tax rate is significant in both $b_{1}$ and $b_{2}$ when it is entered as a determinant of the b's. Indeed its estimated effect is somewhat larger in $b_{2}$. (See appendix table 6.) Results with $\alpha$ and $\beta$ parameterized show that the marginal tax rate is positively related to total saving, $\beta$, but is negatively related to the proportion allocated to IRAs, $\alpha$. These results seem to suggest that the marginal tax rate is picking up an individual-specific saving effect, but seems not related to a particular preference for IRAs. Wise [1984] was unable to identify an effect of the marginal tax rate on tax-deferred saving in Canada, using precisely measured marginal tax rates, as opposed to the self-reported rates used here. 28 While the marginal tax rate enters our budget

28Wise [1984] contains analysis of Canadian tax-deferred Registered Retirement Saving Plans. In general, we have found that the estimated effect of the marginal tax rate is very sensitive to functional form. See also Wise [1985] and Venti and Wise [1985a]. King and Leape [1984] also mention the difficulty of isolating the effect of the marginal tax rate and they conclude: 
constraint as the cost of $S_{1}$, the functional form virtually assures a positive relationship between the tax rate and IRA saving. We do not estimate a price parameter directly. Rather the price enters as a transformation to the data. Indeed the likelihood function is somewhat higher if $P_{1}$ is set to one for everyone, although the effect on the simulations reported below is not substantial.

Thus, while difficult to demonstrate, we believe that the widespread promotion of IRA accounts may be the most important reason for increased saving through their use.

In addition, the estimates do not suggest more IRA saving among persons without than with private pension plans, one of the primary goals of IRA legislation. The coefficient on the pension variable $(-.0140)$ is not significantly different from zero. Furthermore, persons with private pensions save more in the $S_{2}$ form. Results based on the parameterization of $\alpha$ and $\beta$ suggest that while persons without private plans save less, they devote a larger proportion of what they do save to IRAs.

The apparent variation in saving behavior among occupations or other segments of the population has been mentioned by others. 29 The strong relationship of education to IRA saving is consistent with such variation. In its relation to $b_{1}$, a year of education is equivalent to more than two years in age and more than $\$ 30,000$ in liquid wealth. The amount of the marginal dollar devoted to IRAs increases with age but decreases with income.

\footnotetext{
"... contrary to much of the recent 1 iterature, that taxes do not play a decisive role in explaining the difference in portfolio composition across households."
}

${ }^{29}$ See, for example, the survey by King [1985]. 


\section{b. Variants of the Base Specification}

A potentially important restriction in the base specification is that the error variances of $a_{1}$ and $a_{2}$ are equal. While this restriction is not necessary in principle, under the assumption that $S=S_{2}$ only the functional form and the limit $L$ allow identification of the variance of $a_{2}$. Under the assumption that $S=S_{1}+S_{2}$, direct evidence on the residual variance of $S_{2}$ is provided. Estimates based on the assumption that "savings and reserve funds" $S$ include IRAs and allowing separate estimates of $\sigma_{1}$ and $\sigma_{2}$ are presented in appendix table 2. Both variances are estimated rather precisely and are close in magnitude $\left(\hat{\sigma}_{1}=8.84, \hat{\sigma}_{2}=5.45\right)$. Comparison with estimates in appendix table 3 that restrict $\sigma_{1}$ to equal $\sigma_{2}$ shows that the two are not significantly different by a likelihood ratio test. The other findings discussed above are not qualitatively affected if $i t$ is assumed that $s=s_{1}+s_{2}$, except that the residual correlation is now not significantly different from zero. 30

Estimates like those in appendix table 2, but using total wealth only, instead of liquid versus non-liquid wealth, show that total wealth is in fact negatively related to total $s_{1}$ and $s_{2}$ saving and is unrelated to the proportion allocated to $S_{1}$, as mentioned above. (See appendix table 4.) Estimates comparable to appendix table 2, but with $P_{1}=1$ for all persons (ignoring the marginal tax effect) are presented in appendix table 5 . The likelihood value indeed increases, but as shown below, conclusions about the effect of IRA limit changes are not appreciably altered. Estimates with

${ }^{30}$ It can be shown that if $s=s_{2}$ but it is assumed that $s=s_{1}+s_{2}$, the estimated variance of $S_{2}$ will be biased downward. In addition, the estimated residual correlation between $S_{1}$ and $s_{2}$ will be biased downward. 
additive disturbances, instead of random $a_{1}$ and $a_{2}$, are shown in appendix table 7. The estimates are very close to those in text table 7 discussed above.

2. More Flexible Substitution, $\alpha$ and $\beta$ Parameterized

a. With $k=0$

Estimates with $k=0$ are shown in table 8 . They are comparable to those in table 7 , except that $\alpha$ and $\beta$ instead of $b_{1}$ and $b_{2}$, are parameterized, and additive disturbances instead of random $a_{1}$ and $a_{2}$, are used. (Appendix table 7 shows results with $b_{1}$ and $b_{2}$ parameterized and using additive disturbances.) Only estimates assuming $S=S_{2}$ are presented with the more flexible model.31 The basic conclusions are the same as those based on table 7. The mean $\delta_{1}$ is .244 versus .247 in table 7 ; the mean $\delta_{2}, .049$, is somewhat smaller than its table 7 counterpart, .102 , however.

This parameterization, however, indicates total $s_{1}+s_{2}$ saving out of marginal income by $\beta$, and the share of the total to $s_{1}$ by $\alpha$. Some of the conclusions have been discussed above. In addition, the estimates indicate that while total saving increases with age, the proportion allocated to IRAs does not. The more educated save more but allocate a smaller proportion to IRAs, according to these results. Thus it is apparently their greater propensity to save rather than a greater preference for tax-deferred saving that leads to more IRA saving among the educated. As mentioned above, while persons without private pension plans save less, these results indicate that they devote a larger proportion of saving to IRAs. Thus it is apparently

${ }^{31}$ Results with $S=S_{1}+S_{2}$ are presented in Venti and wise [1985b]. 
Table 8. Parameter estimates with $\alpha$ and $\beta$ parameterized, $k=0$.

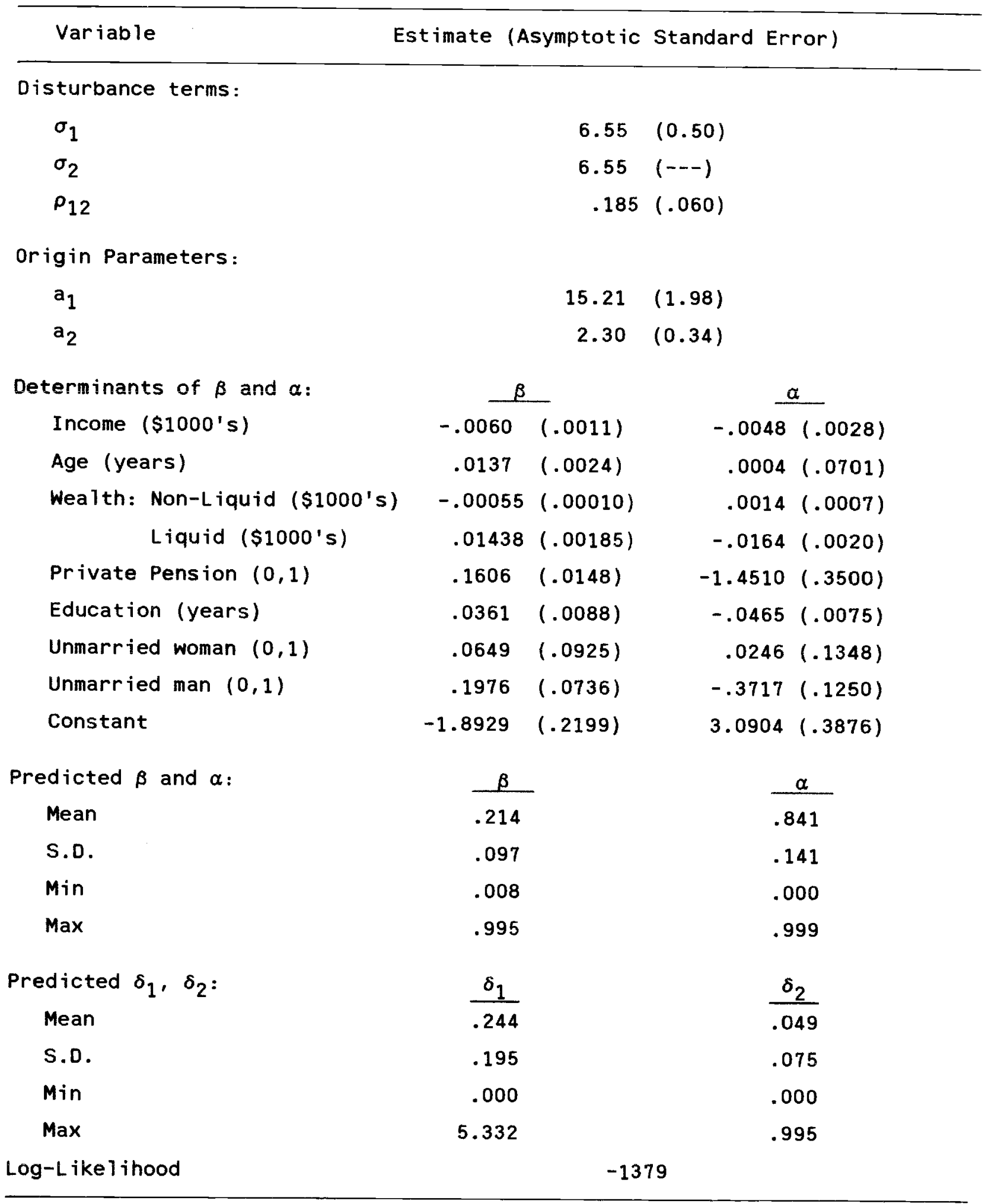


Table 9. Parameter estimates with $\alpha$ and $\beta$ parameterized, $k=.65$

\begin{tabular}{|c|c|c|c|c|}
\hline Variable & \multicolumn{4}{|c|}{ Estimate (Asymptotic Standard Error) } \\
\hline \multicolumn{5}{|l|}{ Disturbance terms: } \\
\hline$\sigma_{1}$ & & 6.61 & $(.542)$ & \\
\hline$\sigma_{2}$ & & 6.61 & $(---)$ & \\
\hline$\rho_{12}$ & & .176 & $(.060)$ & \\
\hline \multicolumn{5}{|l|}{ Origin Parameters: } \\
\hline$a_{1}$ & & 13.61 & $(1.88)$ & \\
\hline$a_{2}$ & & 1.69 & $(0.31)$ & \\
\hline \multirow{2}{*}{$\begin{array}{l}\text { Determinants of } \beta \text { and } \alpha \text { : } \\
\text { Income }\left(\$ 1000^{\prime} s\right)\end{array}$} & \multicolumn{2}{|c|}{$\beta$} & \multicolumn{2}{|c|}{$a$} \\
\hline & -.0059 & $(.0012)$ & -.0026 & $(.0015)$ \\
\hline Age (years) & .0159 & $(.0028)$ & .0000 & $(.0026)$ \\
\hline \multirow{2}{*}{$\begin{aligned} \text { Wealth: } & \left.\text { Non-Liquid ( } \$ 1000^{\prime} s\right) \\
& \left.\text { Liquid ( } \$ 1000^{\prime} s\right)\end{aligned}$} & -.00052 & $(.00011)$ & .00075 & $(.00039)$ \\
\hline & .0148 & $(.0019)$ & -.0088 & $(.0011)$ \\
\hline Private Pension $(0,1)$ & .0821 & $(.0495)$ & -1.7088 & $(.1787)$ \\
\hline Education (years) & .0449 & $(.0118)$ & -.0372 & $(.0061)$ \\
\hline Unmarried woman & .1184 & $(.0948)$ & .9392 & $(.1123)$ \\
\hline Unmarried man & .1830 & $(.0716)$ & -.1918 & $(.0564)$ \\
\hline Constant & -2.2095 & $(.3148)$ & 2.6269 & $(.0011)$ \\
\hline Predicted $\beta$ and $\alpha$ : & \multicolumn{2}{|l|}{$\beta$} & \multicolumn{2}{|c|}{$\alpha$} \\
\hline Mean & \multicolumn{2}{|l|}{.174} & \multicolumn{2}{|c|}{.727} \\
\hline$S . D$ & \multicolumn{2}{|l|}{.096} & \multicolumn{2}{|c|}{.187} \\
\hline $\operatorname{Min}$ & \multicolumn{2}{|l|}{.005} & \multicolumn{2}{|c|}{.000} \\
\hline $\operatorname{Max}$ & \multicolumn{2}{|l|}{.996} & \multicolumn{2}{|c|}{.994} \\
\hline Predicted $\delta_{1}, \delta_{2}:$ & \multicolumn{2}{|l|}{$\delta_{1}$} & \multicolumn{2}{|c|}{$\delta_{2}$} \\
\hline Mean & \multicolumn{2}{|l|}{.213} & \multicolumn{2}{|c|}{.028} \\
\hline S.D. & \multicolumn{2}{|l|}{.189} & \multicolumn{2}{|c|}{.072} \\
\hline Min & \multicolumn{2}{|l|}{.000} & \multicolumn{2}{|c|}{.000} \\
\hline $\operatorname{Max}$ & \multicolumn{2}{|l|}{3.763} & \multicolumn{2}{|c|}{.996} \\
\hline Log-Likelihood & \multicolumn{4}{|c|}{-1394} \\
\hline
\end{tabular}


their lower propensity to save, rather than the same IRA preference as that of private pension holders, that leads to comparable desired IRA contributions among those with and without private pensions.

b. With $k=.65$

Estimates with $k$ set at .65 are shown in table 9. The individual parameter estimates are very close to those with $k=0$, with the exception of the constant terms in $\alpha$ and $\beta$. Again, differences are summarized in the $\delta_{1}$ and $\delta_{2}$ measures. The mean $\delta_{1}$ is .213 when $k=.65$ and .244 with $k=0$. The mean $\delta_{2}$ estimates are .028 and .049 respectively.

The effect of a change in the IRA limit depends in large part on the difference between the share of marginal income allocated to $s_{2}$ by people who are not constrained by the limit and the share allocated to $s_{2}$ by those who are constrained by the limit. These shares are denoted by $\delta_{2}$ and $\delta_{2}^{*}$ respectively. The $i r$ means for $k=0$ and $k=.65$ are as follows:

$\begin{array}{lll}k=0 & \underline{\delta_{2}} & \underline{\delta_{2}^{*}} \\ k=.65 & .091 & .117 \\ & .046 & .096\end{array}$

Thus the predicted relative shift to $S_{2}$ when the constraint is reached is greater when the data are assumed to have been generated by individual saving behavior with greater substitution between $S_{1}$ and $S_{2}$. This is reflected in greater reduction in $S_{2}$ for the $k=.65$ model when the IRA 1 imit is raised than for the $k=0$ model, as indicated in the simulations below. 


\section{The Model Fit}

Although there is some variation in the model fit by specification, the differences are quite small. Thus we present comparison of predicted versus actual values for three illustrative cases. Based on the $k=0$ model, with $\alpha$ and $\beta$ parameterized, table 10 shows simulated versus actual values of the proportion of respondents with $S_{1}>0, S_{1}>L$, and $S>0$, by income interval. Possibly most important are the proportions with $S>0$ conditional on $S_{1}=L$ (at the IRA limit) and with $S>0$ conditional on $S_{1}<0$ (no IRA). overall the fit is very close. In particular, the model seems not to underestimate the $S_{2}$ saving of persons who are at the IRA limit, as might be expected if not enough substitution of $s_{2}$ for $s_{1}$ were allowed by the model when the $S_{1}$ limit is reached. But this simulation shows some over-prediction of $\mathrm{S}_{2}$ saving for persons below the IRA limit. The simulated predictions are based on only 10 draws per person, however, so they reflect some random variation. 32 While unconditional overall proportions will match the actual values closely, nothing in the specifications assures a close fit by income interval. The model over-predicts saving of low-income persons. This is a characteristic of all of the specifications.

This over-prediction is eliminated if the disturbance terms are allowed to be heteroskedastic, with the variance increasing with income, by specifying $\epsilon_{1}=n_{1} Y+e_{1}$ and $\epsilon_{2}=n_{2} \gamma+e_{2} \cdot 33$ The fit based on this model with

32 In eight different simulations with 10 draws per person in each the average of the predicted proportion of those with $S>0$ given $S_{1}=L$ was .676 .

${ }^{33}$ Similar results were obtained by wise [1984, 1985] using Canadian data and by Vent $i$ and Wise [1985a] using Current Population Survey data. 
Table 10. Simulated predicted vs actual values, by income interval, $k=0 .{ }^{a}$

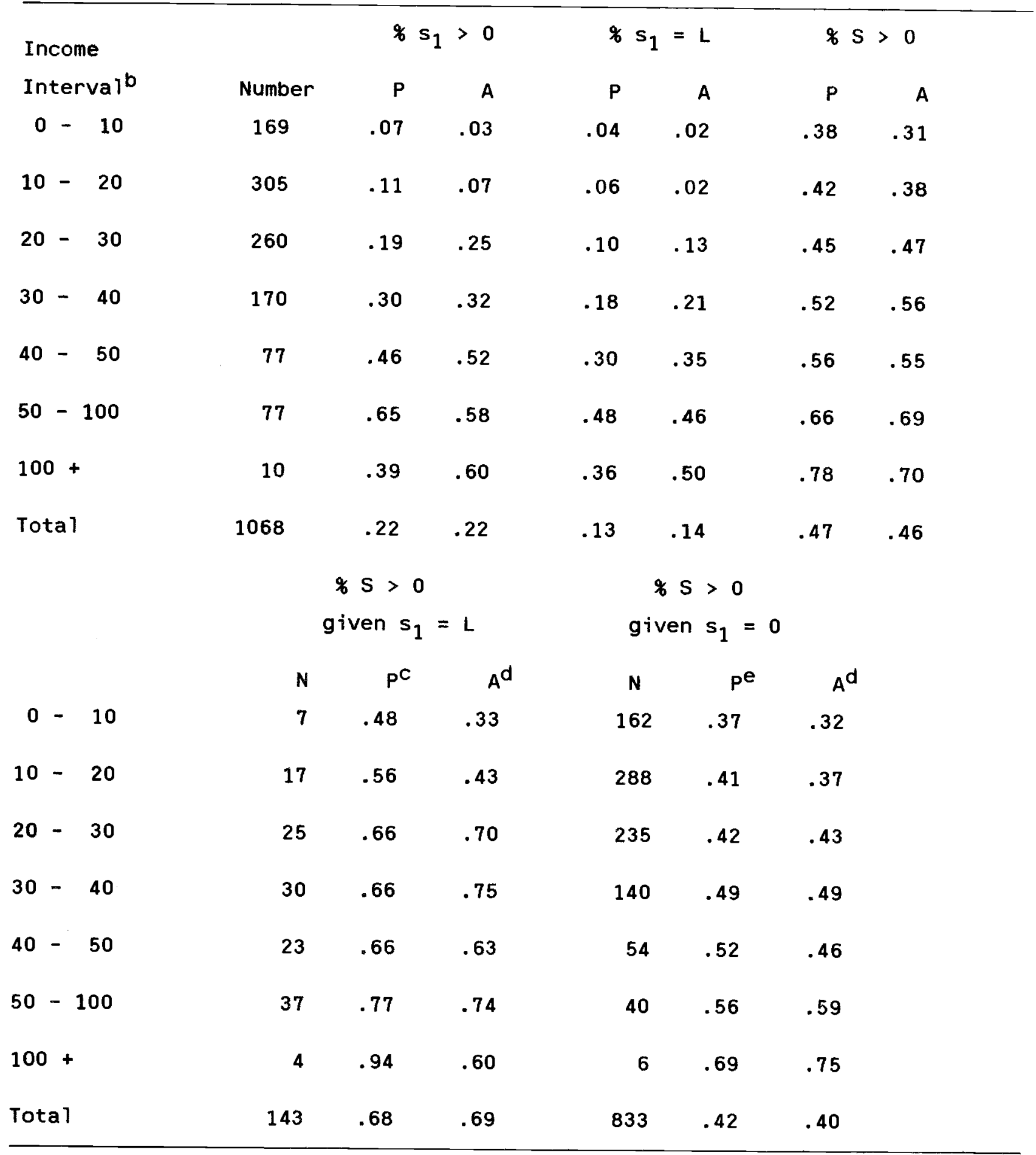

a. Based on 10 draws per sample observation.

b. $Y-T$, in thousands of dollars.

c. Predicted $S>0$, given predicted $S_{1}=L$.

d. Observed in the sample.

e. Predicted $S>0$, given predicted $S_{1}<0$. 
Table 11. Simulated predicted vs actual values, by income interval, $k=0$, and heteroskedastic disturbance terms. ${ }^{a}$

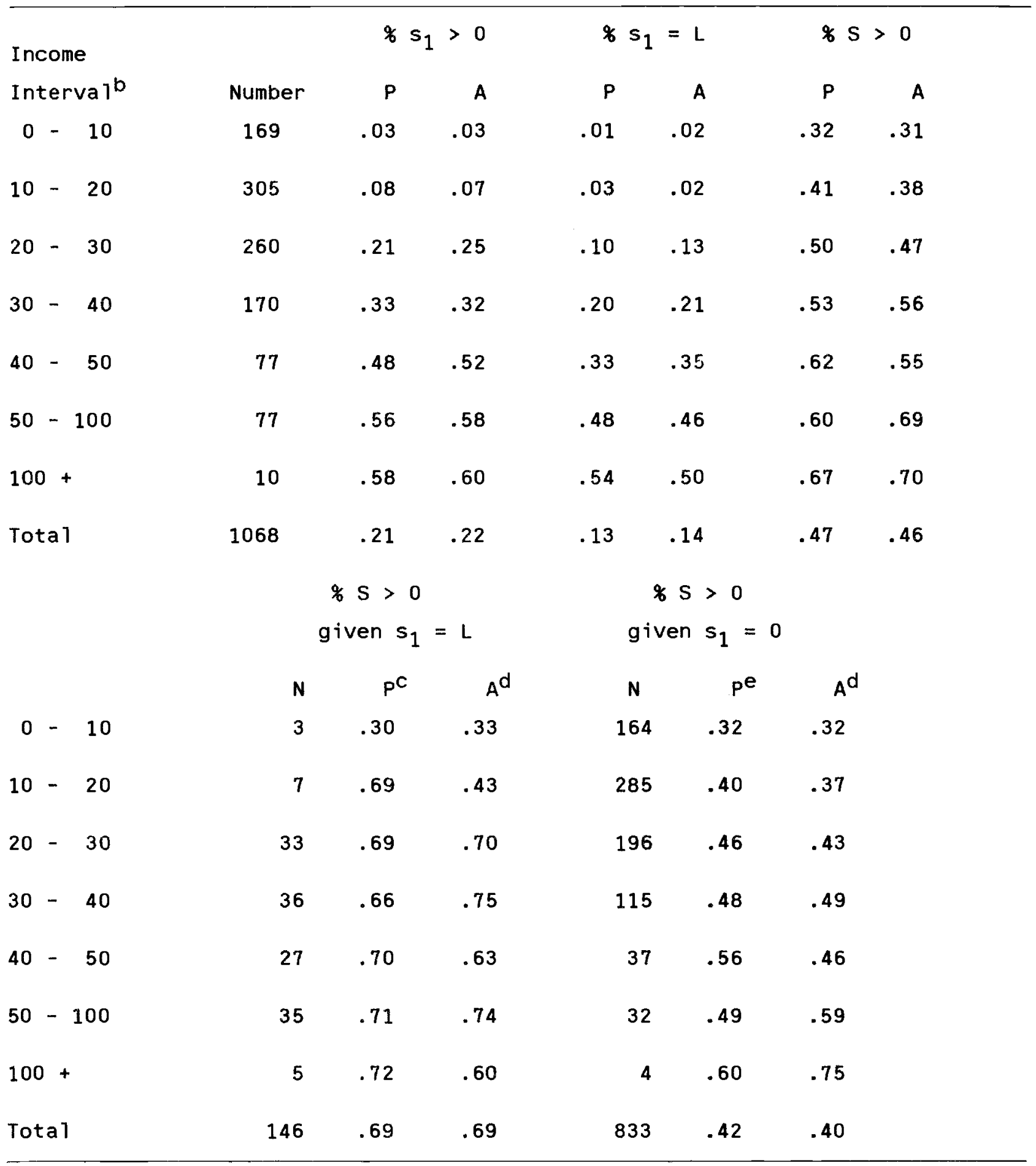

a. Based on 10 draws per sample observation.

b. $\quad Y-T$, in thousands of dollars.

c. Predicted $S>0$, given predicted $S_{1}=L$.

d. Observed in the sample.

e. Predicted $S>0$, given predicted $S_{1}<0$. 
Table 12. Simulated predicted vs actual values, by income interval, $k=.65 . a$

\begin{tabular}{|c|c|c|c|c|c|c|c|c|}
\hline \multicolumn{2}{|c|}{ Income } & \multicolumn{3}{|c|}{$\% s_{1}>0$} & \multicolumn{2}{|c|}{$* s_{1}=L$} & $\% 5>$ & 0 \\
\hline \multicolumn{2}{|c|}{ Interva ${ }^{b}$} & Number & $P$ & A & $P$ & A & $P$ & A \\
\hline & -10 & 169 & .08 & .03 & .04 & .02 & .40 & .31 \\
\hline 10 & -20 & 305 & .11 & .07 & .06 & .02 & .44 & .38 \\
\hline 20 & -30 & 260 & .20 & .25 & .12 & .13 & .45 & .47 \\
\hline 30 & -40 & 170 & .28 & .32 & .15 & .21 & .48 & .56 \\
\hline 40 & -50 & 77 & .44 & .52 & .31 & .35 & .52 & .55 \\
\hline & -100 & 77 & .63 & .58 & .48 & .46 & .61 & .69 \\
\hline 100 & + & 10 & .38 & .60 & .33 & .50 & .77 & .70 \\
\hline \multirow{4}{*}{\multicolumn{2}{|c|}{ Tota 1}} & 1068 & .22 & .22 & .14 & .14 & .46 & .46 \\
\hline & & \multicolumn{3}{|c|}{$\% s>0$} & \multicolumn{2}{|c|}{$* s>0$} & & \\
\hline & & \multicolumn{3}{|c|}{ given $s_{1}=L$} & \multicolumn{3}{|c|}{ given $s_{1}=0$} & \\
\hline & & $N$ & $p^{C}$ & $A^{d}$ & $N$ & pe & $A^{d}$ & \\
\hline 0 & $-\quad 10$ & 8 & .52 & .33 & 162 & .40 & .32 & \\
\hline 10 & $-\quad 20$ & 19 & .68 & .43 & 286 & .42 & .37 & \\
\hline 20 & $-\quad 30$ & 30 & .63 & .70 & 230 & .43 & .43 & \\
\hline 30 & $-\quad 40$ & 26 & .61 & .75 & 144 & .45 & .49 & \\
\hline 40 & $-\quad 50$ & 24 & .64 & .63 & 54 & .47 & .46 & \\
\hline 50 & -100 & 37 & .72 & .74 & 40 & .51 & .60 & \\
\hline 100 & + & 3 & .94 & .60 & 7 & .69 & .75 & \\
\hline Tota & & 146 & .66 & .69 & 835 & .42 & .40 & \\
\hline
\end{tabular}

a. Based on 10 draws per sample observation.

b. $Y-T$, in thousands of dollars.

c. Predicted $S>0$, given predicted $S_{1}=L$.

d. Observed in the sample.

e. Predicted $S>0$, given predicted $s_{1}<0$. 
$k=0$ is shown in table 11, where it can be seen that the predicted and actual proportions are very close for all income groups. Finally, illustrative predictions with $k=.65$ are shown in table 12 . The predicted versus actual values are very similar to those in the $k=0$ case, although if anything the predicted proportion of those at the limit with $S>0$ is somewhat lower than in the $k=0$ case. ${ }^{34}$ Predictions with $b_{1}$ and $b_{2}$ parameterized are shown in appendix table 8 , based on the estimates in table 7 . This specification tends to predict a lower portion of those at the limit with $S>0$ than the mode 1 with $\alpha$ and $\beta$ parameterized.

\section{Simulations of the Effect of IRA Limit Changes}

To estimate the effect of IRAs on saving, we have predicted the effect of limit changes on IRA contributions and on other saving. To add content to this exercise, we have simulated the effects of several recently proposed limit changes. The first we call the Treasury Plan.35 It would increase the limit for an employed person from $\$ 2000$ to $\$ 2500$, and would increase the limit for a nonworking spouse from $\$ 250$ to $\$ 2500$. Thus, for example, the contribution limit for a husband and nonworking wife would increase from $\$ 2250$ to $\$ 5000$. A Modified Treasury Plan increases the limit for an employed person from $\$ 2000$ to $\$ 2500$, but only increases the 1 imit for a nonworking spouse to $\$ 500$, from $\$ 250$. Finally, the President's Plan would

\footnotetext{
34 The average over eight simulations with 10 draws per person in each was .656 , versus .676 in the $k=0$ case. The average over three simulations with 50 draws per person in each was .652 .

${ }^{35}$ see U.S. Department of Treasury [1984].
} 
leave the $1 \mathrm{imit}$ for an employed person at $\$ 2000$, but would raise the $1 \mathrm{imit}$ for a nonworking spouse from $\$ 250$ to $\$ 2000.36$ For comparison, simulated savings under the current limit are also shown.

The predicted changes should be interpreted as indications of changes in saving had the IRA limit been higher in 1982 . It is important to keep in mind that $s_{2}$ saving undoubtedly excludes changes in non-liquid wealth such as housing. The possible substitution between IRAs and housing wealth in the long run, for example, would not be reflected in these estimates. They are intended, however, to indicate the extent to which IRA contributions in 1982 were simply a substitute for other forms of saving, other than non-liquid assets. The top portion of the table pertains to individuals who are predicted to be at the IRA limit, since it is only this group that would be affected by an increase in the limit. The bottom portion shows simulated contributions by family type. The simulations are based on the estimation sample. Those in table 13 are based on the estimates in table 7 and those in table 14 on the $k=.65$ estimates shown in table 9 . The simulated values are based on 10 random draws for each observation in the estimation sample.

The predicted changes in $S_{1}$ and $S_{2}$ under the treasury plan for families at the IRA limit, for example, are as follows:

${ }^{36}$ See U.S. President [1985]. 


$\begin{array}{lll} & \frac{\Delta \mathrm{S}_{1}}{} & \frac{\Delta \mathrm{S}_{2}}{} \\ \text { Base model } & +1138 & -94 \\ \mathrm{k}=.65 & +1091 & -210\end{array}$

These values suggest that only ten to twenty percent of the IRA increase is offset by a reduction in other financial assets. Thus at least in the short run, tax-deferred IRA accounts have by these estimates led to a relatively large increase in total individual saving (as defined in this paper). Possibly the best indicator of saving is change in consumption. The average change in "consumption" (as defined implicitly in this paper) under each plan is shown in table 15 together with changes in $S_{2}$ and in taxes. For example, the simulated changes under the Treasury Plan for families at the limit are:

\begin{tabular}{lcccc} 
& \multicolumn{2}{c}{ Base Model } & \multicolumn{2}{c}{$\underline{k=.65 \text { Model }}$} \\
& Amount & Percent & Amount & Percent \\
IRA, S 1 Saving & +1138 & 100.0 & +1091 & 100.0 \\
$\mathrm{~S}_{2}$ Saving & -94 & -8.3 & -210 & -19.2 \\
Consumption & -643 & -56.5 & -493 & -45.2 \\
Taxes & -401 & -35.2 & -388 & -35.6
\end{tabular}

Thus possibly fifty percent of the IRA increase is funded by a reduction in consumption, according to these measures, and possibly thirty-five percent by reduced taxes, with a relatively small proportion coming from reduction in other saving. 
Table 13. Simulated increases in IRA contributions and in other saving, by plan and family type, table 7 parameter estimates, $b_{1}$ and $b_{2}$
parameterized, and $k=0$.

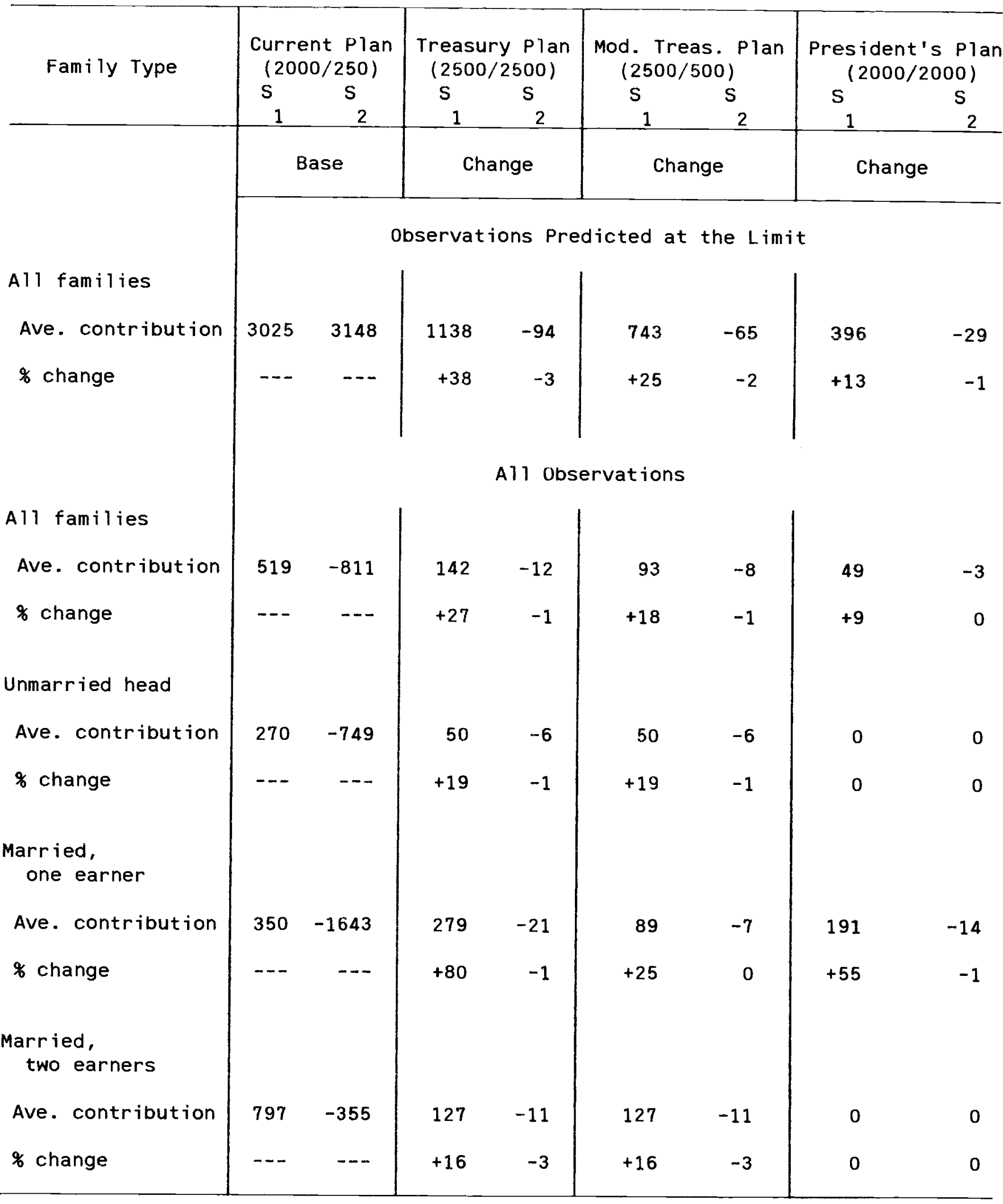


Table 14. Simulated increases in IRA contributions and in other saving, by plan and family type, using table 9 parameter estimates, $\alpha$ and $\beta$ parameterized, and $k=.65$.

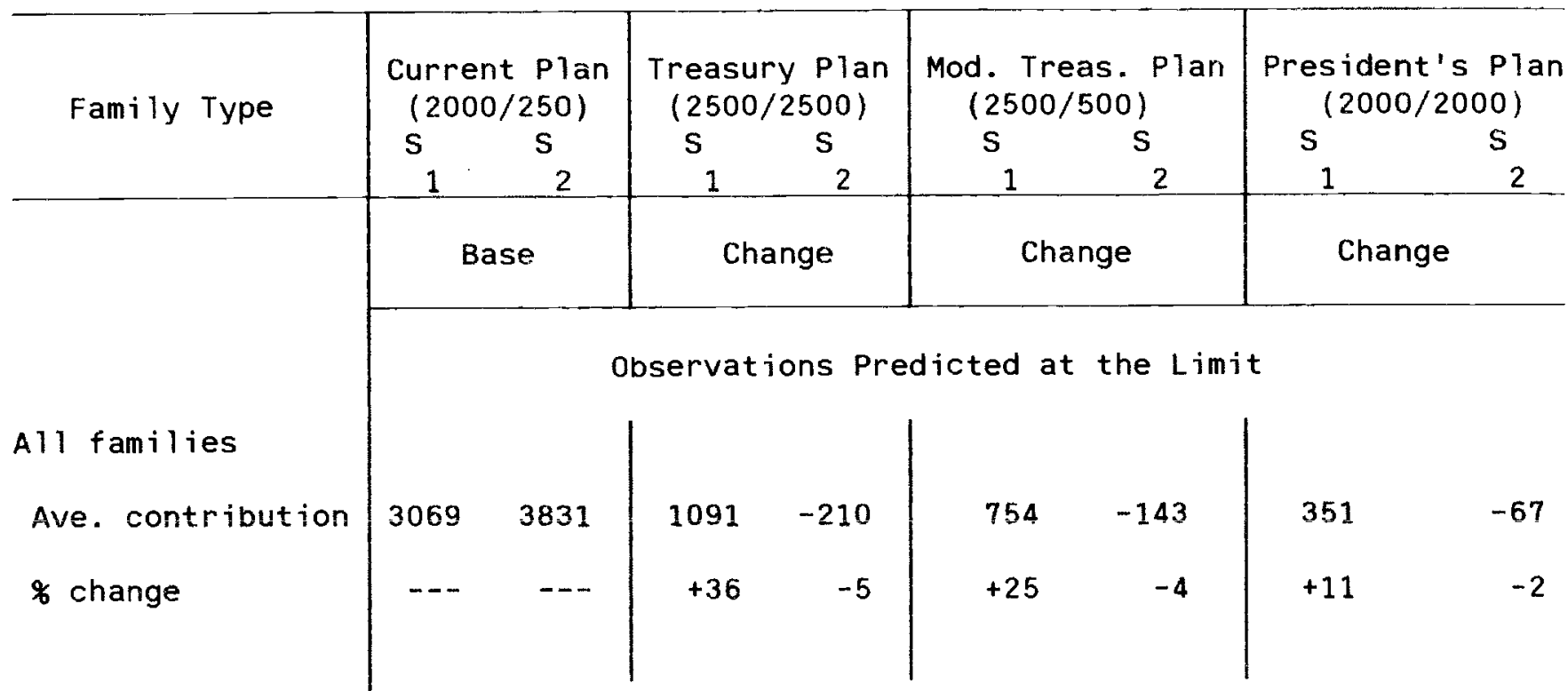

All families

Ave. contribution

\% change

Unmarried head

Ave. contribution

\% change

Married, one earner

Ave. contribution

\% change

Married,

two earners

Ave contribution

$\%$ change
A11 Observations

\begin{tabular}{|c|c|c|c|c|c|c|}
\hline 111 & 143 & -28 & 99 & -19 & 46 & -9 \\
\hline$\cdots$ & +27 & -25 & +19 & -17 & +9 & -8 \\
\hline-471 & 51 & -10 & 51 & -10 & 0 & 0 \\
\hline--- & +19 & -2 & +19 & -2 & 0 & 0 \\
\hline 14 & 255 & -49 & 85 & -15 & 177 & -34 \\
\hline--- & +74 & & +25 & & +51 & \\
\hline
\end{tabular}


Table 15. Simulated changes in saving, consumption, and taxes, by plan and by model specification.

\begin{tabular}{l|c|c|c}
\hline & $\begin{array}{c}\text { Treasury Plan } \\
2500 / 2500 \\
\text { Amount Percent }\end{array}$ & $\begin{array}{c}\text { Modified Treasury } \\
\text { Plan, 2500/500 } \\
\text { Amount Percent }\end{array}$ & $\begin{array}{c}\text { President's Plan } \\
2000 / 2000 \\
\text { Amount Percent }\end{array}$ \\
\hline
\end{tabular}

Base Mode 1

\begin{tabular}{|c|c|c|c|c|c|c|}
\hline$\Delta \mathrm{S}_{1}$ saving & 1138 & $(100.0)$ & 743 & $(100.0)$ & 396 & $(100.0)$ \\
\hline$\Delta \mathrm{S}_{2}$ saving & -94 & $(8.3)$ & -65 & $(8.7)$ & -29 & $(7.3)$ \\
\hline$\Delta$ Consumption & -643 & $(56.5)$ & -421 & $(56.7)$ & -228 & $(57.6)$ \\
\hline$\Delta$ Taxes & -401 & $(35.2)$ & -257 & $(34.6)$ & 139 & $(35.1)$ \\
\hline \multicolumn{7}{|l|}{ All Families } \\
\hline$\Delta \mathrm{S}_{1}$ saving & 142 & $(100.0)$ & 93 & $(100.0)$ & 49 & $(100.0)$ \\
\hline$\Delta S_{2}$ saving & -12 & $(8.5)$ & -8 & $(8.6)$ & -3 & $(6.1)$ \\
\hline$\Delta$ Consumption & -81 & $(57.0)$ & -53 & $(57.0)$ & -29 & $(59.2)$ \\
\hline \multirow[t]{2}{*}{$\Delta$ Taxes } & -49 & $(34.5)$ & -32 & $(34.4)$ & -17 & $(34.7)$ \\
\hline & \multicolumn{6}{|c|}{$\mathrm{k}=.65$ Model } \\
\hline \multicolumn{7}{|l|}{ Families at Limit } \\
\hline$\Delta \mathrm{S}_{1}$ saving & 1091 & $(100.0)$ & 754 & $(100.0)$ & 351 & $(100.0)$ \\
\hline$\Delta S_{2}$ saving & -210 & $(19.2)$ & -143 & $(19.0)$ & -67 & $(19.1)$ \\
\hline$\Delta$ Consumption & -493 & $(45.2)$ & -344 & $(45.6)$ & -162 & $(46.2)$ \\
\hline$\Delta$ Taxes & -388 & $(35.6)$ & -267 & $(35.4)$ & -122 & $(34.8)$ \\
\hline \multicolumn{7}{|l|}{ All Families } \\
\hline$\Delta \mathrm{S}_{1}$ saving & 143 & $(100.0)$ & 99 & $(100.0)$ & 46 & $(100.0)$ \\
\hline$\Delta S_{2}$ saving & -28 & $(19.6)$ & -19 & $(19.2)$ & -9 & $(19.6)$ \\
\hline$\Delta$ Consumption & -65 & $(45.5)$ & -45 & $(45.5)$ & -21 & $(45.7)$ \\
\hline$\Delta$ Taxes & -50 & $(35.0)$ & -35 & $(35.4)$ & -16 & $(34.8)$ \\
\hline
\end{tabular}


The estimated IRA increases can be compared with estimates by Venti and Wise [1985a] based on 1983 Current Population Survey (CPS) data. The CPS data reported actual 1982 IRA contributions by interval, while 1982 contributions had to be inferred from balances reported in the SCF. In addition, self-reported marginal tax rates were used here, while estimated rates were used in conjunction with the CPS data. Nonetheless the simulated effects of limit increases are virtually the same. For example, for all families the simulated increase under the Treasury Plan is twenty-seven percent versus thirty percent based on the CPS data. The increase for unmarried heads is nineteen percent versus nineteen percent based on the CPS; it is eighty percent versus seventy-nine percent for married one-earner families; and sixteen percent versus sixteen percent for married two-earner families.

\section{E. Sensitivity of Results to Model Specification}

The sensitivity of the results to selected specification changes is shown in table 16. Possibly the best summary indicator of the effect of these changes is the simulated change in $s_{2}$ under the Treasury Plan. In each case, the decline in $S_{2}$ is small relative to the increase in IRAs, although the magnitude of the decline in $s_{2}$ varies by a factor of four. None of the specification changes has much effect on the simulated IRA change. Assuming that $S=S_{1}+S_{2}$ tends to reduce the estimated reduction in $S_{2}$, except where $P_{1}$ is set to 1 . In the latter case, the constrained estimate $\delta_{2}^{*}$ of $\delta_{2}$ is larger because $\hat{b}_{2} /\left(1-\hat{b}_{1}\right)$ is larger.

IV. Conclusions

Increasing the IRA limits would lead to substantial increases in tax- 
Table 16. Sensitivity of simulations to alternative specifications

\begin{tabular}{|c|c|c|c|c|c|}
\hline \multirow[b]{2}{*}{ Specification } & \multirow[b]{2}{*}{ LF } & \multirow[b]{2}{*}{$\delta_{1}$} & \multirow[b]{2}{*}{$\delta_{2}$} & \multicolumn{2}{|c|}{$\begin{array}{l}\text { Treasury Plan Effect for } \\
\text { Persons at the Limit }\end{array}$} \\
\hline & & & & $\Delta \mathrm{S}_{1}$ & $\Delta \mathrm{S}_{2}$ \\
\hline \multicolumn{6}{|l|}{$S=s_{2}:$} \\
\hline$b_{1}, b_{2}$ parameterized & -1380 & .247 & .102 & 1138 & -94 \\
\hline $\begin{array}{l}b_{1}, b_{2} \text { parameterized; } \\
\text { stocks \& bonds included } \\
\text { with liquid assets }\end{array}$ & -1399 & .268 & .103 & 1135 & -95 \\
\hline $\begin{array}{l}b_{1}, b_{2} \text { parameterized; } \\
\text { additive errors }\end{array}$ & -1377 & .240 & .078 & 1144 & -83 \\
\hline $\begin{array}{l}k=0 ; \alpha, \beta \text { parameterized; } \\
\text { additive errors }\end{array}$ & -1379 & .244 & .049 & 1111 & -69 \\
\hline $\begin{array}{l}k=.65 ; \alpha, \beta \text { parameterized } \\
\text { additive errors }\end{array}$ & -1394 & .213 & .028 & 1091 & -210 \\
\hline \multicolumn{6}{|c|}{$S=S_{1}+S_{2} ; b_{1} ; b_{2}$ parameterized: } \\
\hline$\sigma_{1} \ddagger \sigma_{2}$ & -1377 & .287 & .059 & 1137 & -52 \\
\hline$\sigma_{1}=\sigma_{2}$ & -1378 & .254 & .085 & 1141 & -76 \\
\hline Total wealth only & -1381 & .294 & .061 & 1143 & -45 \\
\hline$P_{1}=1$ & -1363 & .403 & .096 & 1130 & -172 \\
\hline
\end{tabular}


deferred saving according to our evidence, based on the 1983 Survey of Consumer Finances. For example, the recent Treasury Plan would increase IRA contributions by about thirty percent. Virtually the same estimate was obtained in previous analysis based on Current Population Survey data, suggesting that this conclusion may be relatively robust. The primary focus of this paper, however, has been the effect of limit increases on other saving. How much of the IRA increase would be offset by reduction in non-taxdeferred saving? The weight of our evidence suggests that very little of the increase would be offset by reduction in other financial assets, possibly ten to twenty percent, maybe less. Our estimates suggest that fortyfive to fifty-five percent of the IRA increase would be funded by reduction in consumption, and about thirty-five percent by reduced taxes.

The analysis rests on a preference structure recognizing the constraint that the IRA limit places on the allocation of current income. The model fits the data well and in particular distinguishes accurately the savings decisions of persons at the IRA limit versus those who are not.

The greatest potential uncertainty about the results and the greatest statistical complication for analysis stems from the limited information on non-IRA saving and thus the difficulty of obtaining direct estimates of the degree of substitution between tax-deferred and non-tax-deferred saving. We have addressed these issues by considering the sensitivity of our conclusions to specification changes, including assumptions about the interpretation of key variables and the extent of substitution underlying observed saving outcomes. Although the magnitude of the estimated reduction in other saving, with increases in the IRA limit, is sensitive to specification changes, the 
reduction as a percent of the IRA increase is invariably small.

In addition to these primary conclusions, our evidence suggests substantial variation in saving behavior among segments of the population. We also find that IRAs do not serve as a substitute for private pension plans, although persons without private plans devote a larger proportion of their lower total saving to IRAs. Thus the legislative goal of disproportionately increasing retirement saving among persons without pension plans is apparently not being realized. But the more general goal of increasing individual saving is. 
Appendix A: Imputing 1982 IRA Contributions

The Survey of Consumer Finances (SCF) asked respondents if they had any IRA accounts and the total dollar value in all of them. The SCF did not ask respondents for their 1982 contribution. Given that ERTA liberalized eligibility beginning in 1982 (nearly $3 / 4$ of all 1982 accounts were opened in 1982), the following criteria are used to impute 1982 contributions:

(a) If the total value of IRAs is less than the 1982 family limit then the total value is assumed to be the 1982 contribution.

(b) If the total value of IRAs exceeds the 1982 family limit then the family limit is assumed to be the 1982 contribution.

Imputed IRA contributions based on this procedure compare favorably to evidence from the CPS, which presents 1982 contributions by interval. 
Appendix Table 1: Summary statistics for estimation subsample

\begin{tabular}{|c|c|c|c|c|c|}
\hline \multirow[t]{2}{*}{ Variable } & \multicolumn{2}{|c|}{ A11 } & \multirow[t]{2}{*}{1} & \multicolumn{2}{|c|}{ Contributors Only } \\
\hline & Mean & S.D. & & Mean & S.D. \\
\hline \multicolumn{6}{|l|}{ Total After-tax } \\
\hline Income $(Y-T)^{d}$ & 26239 & 22442 & & 41093 & 30354 \\
\hline Age & 37.7 & 11.4 & & 44.0 & 11.2 \\
\hline Wealth ${ }^{b}$ & 59781 & 115927 & & 120628 & 169900 \\
\hline Liquid wealth & 7796 & 19109 & & 17974 & 30156 \\
\hline Non-liquid wealth & 51984 & 109231 & & 102654 & 160011 \\
\hline Private pension $(0,1)^{\mathrm{C}}$ & 0.67 & 0.47 & & 0.80 & 0.40 \\
\hline Education (years) & 13.4 & 2.5 & & 14.5 & 2.3 \\
\hline Unmarried woman $(0,1)$ & 0.17 & 0.38 & & 0.10 & 0.30 \\
\hline Unmarried man $(0,1)$ & 0.14 & 0.35 & & 0.11 & 0.31 \\
\hline Marginal tax rate & 0.25 & 0.15 & & 0.31 & 0.14 \\
\hline IRA (\$) & 533 & 1164 & & 2423 & 1257 \\
\hline$I R A>0(0,1)$ & 0.22 & 0.41 & & - & - \\
\hline "S" $\quad(0,1)$ & 0.46 & 0.50 & & 0.65 & 0.48 \\
\hline$N$ of observations & & & & & \\
\hline
\end{tabular}

a. Total after-tax income is obtained by using the reported marginal tax rate and inferred filing status to calculate (using 1982 tax tables) the taxes paid by each family, and subtracting this amount from total income.

b. The wealth variables are defined in footnote 4 .

c. For two worker families the variable is unity if either member participates in a pension plan, and zero otherwise. 
Appendix Table 2. Parameter estimates with $b_{1}$ and $b_{2}$ parameterized, assuming that $S=S_{1}+S_{2}, \sigma_{1} \neq \sigma_{2}$.

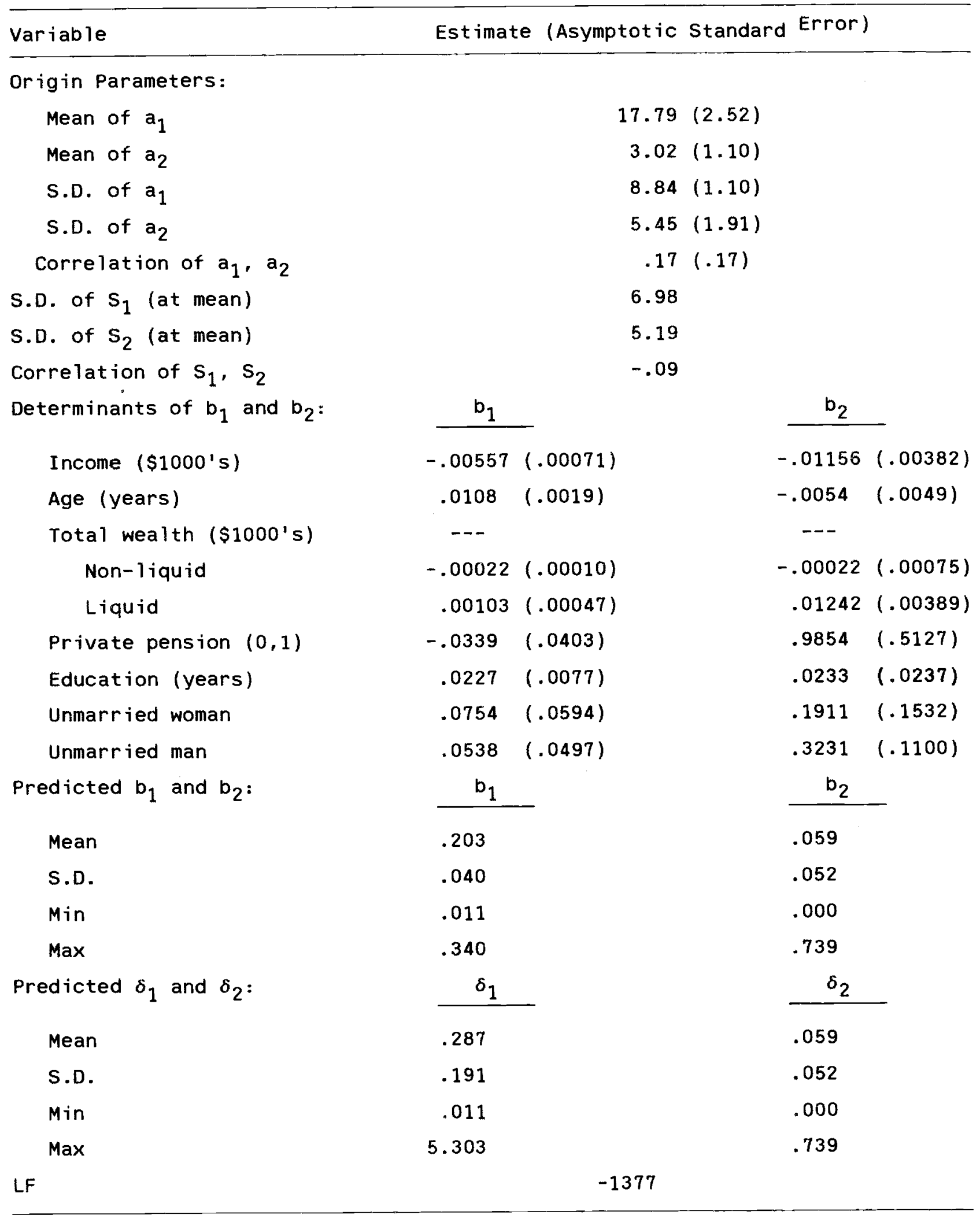


Appendix Table 3. Parameter estimates with $b_{1}$ and $b_{2}$ parameterized, assuming that $S=S_{1}+S_{2}, \sigma_{1}=\sigma_{2}$.

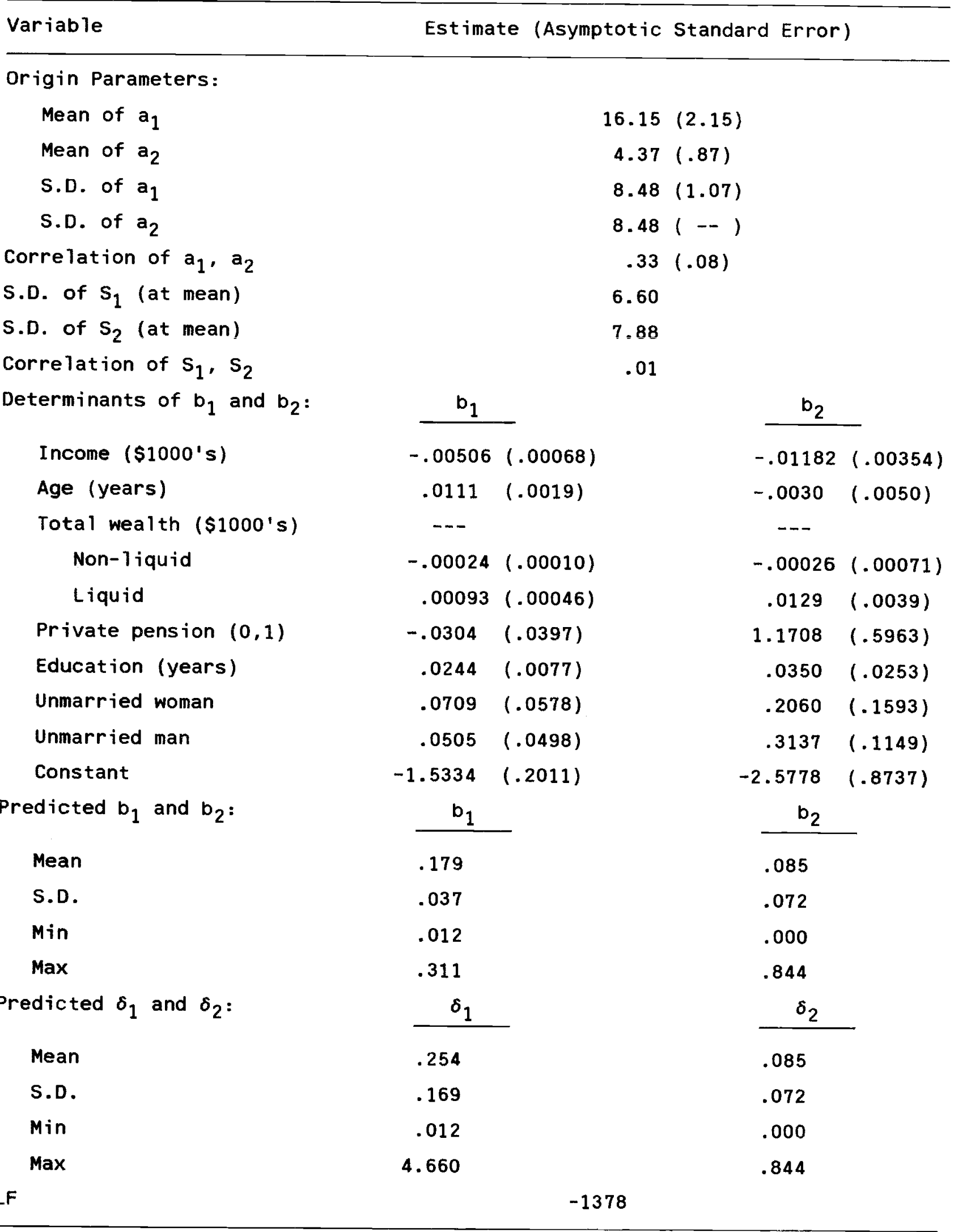


Appendix Table 4. Parameter estimates with $b_{1}$ and $b_{2}$ parameterized, assuming that $S=S_{1}+S_{2}, \sigma_{1} \ddagger \sigma_{2}$, using total wealth.

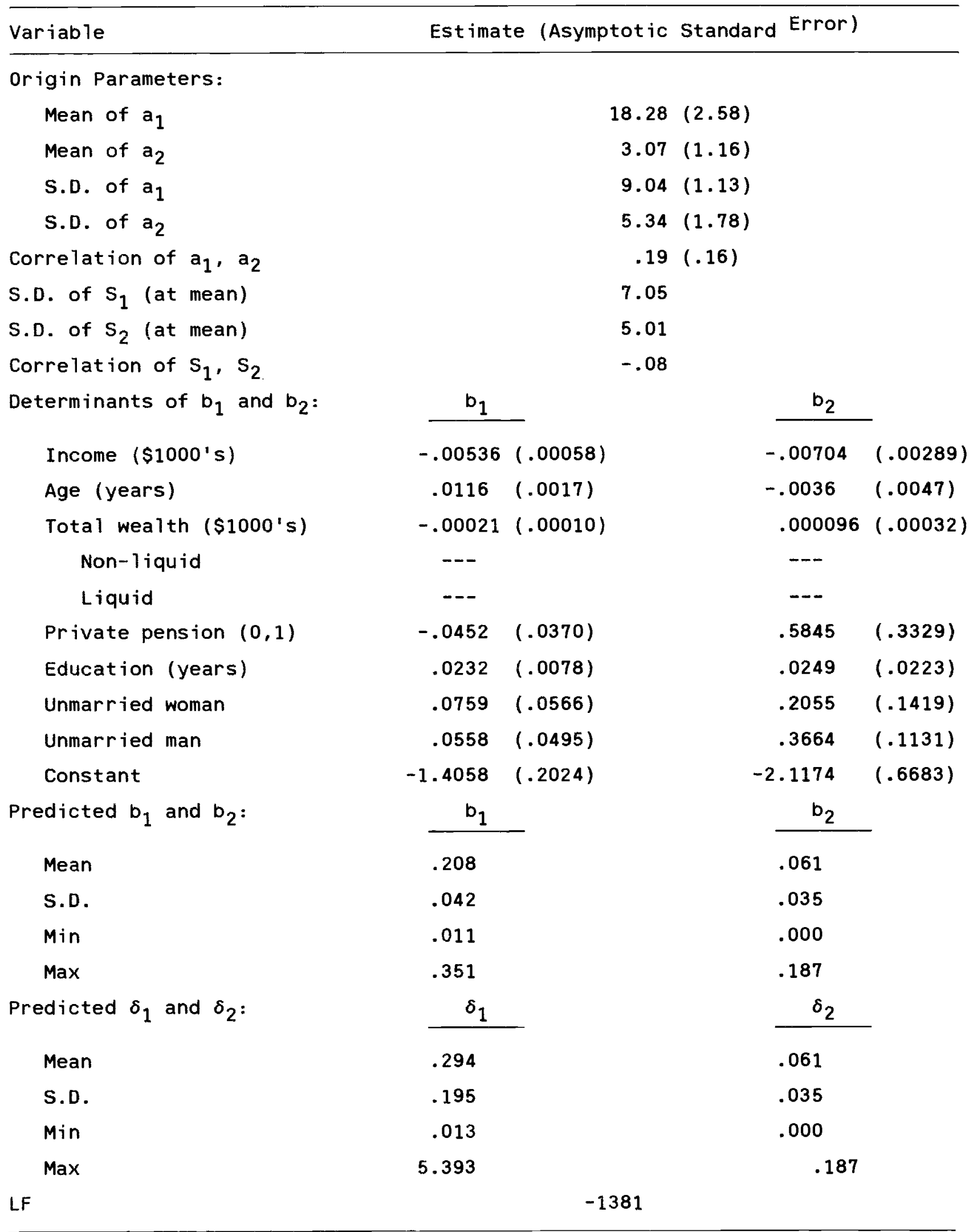


Appendix Table 5. Parameter estimates with $b_{1}$ and $b_{2}$ parameterized, assuming that $S=S_{1}+S_{2}, \sigma_{1} \neq \sigma_{2}$, and $P_{1}=1$.

\begin{tabular}{|c|c|c|c|c|}
\hline Variable & Estimate & e (Asymptotic & Standard Error) & \\
\hline \multicolumn{5}{|l|}{ Origin Parameters: } \\
\hline Mean of $a_{1}$ & & 31.29 & $(6.96)$ & \\
\hline Mean of $a_{2}$ & & 6.24 & $(3.26)$ & \\
\hline S.D. of $a_{1}$ & & 13.23 & $(3.08)$ & \\
\hline S.D. of $a_{2}$ & & 9.65 & $(4.55)$ & \\
\hline Correlation of $a_{1}, a_{2}$ & & .54 & $(.22)$ & \\
\hline S.D. of $\mathrm{S}_{1}$ (at mean) & & 6.66 & & \\
\hline S.D. of $S_{2}$ (at mean) & & 8.26 & & \\
\hline Correlation of $s_{1}, s_{2}$ & & -.05 & & \\
\hline Determinants of $b_{1}$ and $b_{2}$ : & $\mathrm{b}_{1}$ & & $b_{2}$ & \\
\hline Income (\$1000's) & -.00685 & $(.00077)$ & -.00853 & $(.00247)$ \\
\hline Age (years) & .0078 & $(.0017)$ & -.0042 & $(.0037)$ \\
\hline Total wealth (\$1000's) & -- & & --- & \\
\hline Non-liquid & -.000093 & $(.000087)$ & -.00016 & $(.00048)$ \\
\hline Liquid & .00205 & $(.00046)$ & .00797 & $(.00293)$ \\
\hline Private pension $(0,1)$ & -.0064 & $(.0313)$ & .5626 & $(.2495)$ \\
\hline Education (years) & .0213 & $(.0066)$ & .0158 & $(.0179)$ \\
\hline Unmarried woman & .0670 & $(.0458)$ & .1331 & $(.1153)$ \\
\hline Unmarried man & .0469 & $(.0392)$ & .2444 & $(.0911)$ \\
\hline Constant & -.6726 & $(.2384)$ & -1.6834 & $(.5608)$ \\
\hline Predicted $b_{1}$ and $b_{2}$ : & $\mathrm{b}_{1}$ & & $\mathrm{~b}_{2}$ & \\
\hline Mean & .403 & & .096 & \\
\hline S.D. & .052 & & .048 & \\
\hline Min & .023 & & .000 & \\
\hline $\operatorname{Max}$ & .599 & & .540 & \\
\hline Predicted $\delta_{1}$ and $\delta_{2}$ : & $\delta_{1}$ & & $\delta_{2}$ & \\
\hline Mean & .403 & & .096 & \\
\hline S.D. & .052 & & .048 & \\
\hline Min & .023 & & .000 & \\
\hline $\operatorname{Max}$ & .599 & & .540 & \\
\hline$F$ & & -1363 & & \\
\hline
\end{tabular}


Appendix Table 6 . Parameter estimates with $b_{1}$ and $b_{2}$ parameterized, assuming $S=S_{1}+S_{2}, \sigma_{1} \neq \sigma_{2}, P_{1}=1$, and marginal tax rate in $b_{1}$ and $b_{2}$.

Variable

Estimate (Asymptotic Standard Error)

Origin Parameters:

Mean of $a_{1}$

Mean of $a_{2}$

S.D. of $a_{1}$

S.D. of $a_{2}$

Correlation of $a_{1}, a_{2}$

S.D. of $\mathrm{S}_{1}$ (at mean)

S.D. of $S_{2}$ (at mean)

Correlation of $s_{1}, s_{2}$

Determinants of $b_{1}$ and $b_{2}$ :

Income ( $\left.\$ 1000^{\prime} s\right)$

Age (years)

Total wealth (\$1000's)

Non-liquid

Liquid

Private pension $(0,1)$

Education (years)

Unmarried woman

Unmarried man

Marginal tax rate

Constant

Predicted $b_{1}$ and $b_{2}$ :

Mean

S.D.

Min

$\operatorname{Max}$

Predicted $\delta_{1}$ and $\delta_{2}$ :

Mean

Standard deviation

Min

$\operatorname{Max}$

$\begin{aligned} & 32.73(7.59) \\ & 7.45(3.45) \\ & 13.20(3.13) \\ & 10.06(4.16) \\ & .57(.20) \\ & 6.42 \\ & 8.23 \\ &-.10\end{aligned}$

$\mathrm{b}_{1}$

$-.00763(.00077)$

$-.00915(.00230)$

$.0076 \quad(.0016)$

$-.0051 \quad(.0032)$

-

$-.000112(.000080)$

$-.000163(.00041)$

$.00241 \quad(.00049)$

$.00777 \quad(.00274)$

$-.0469 \quad(.0315)$

$.3478 \quad(.1426)$

$.0198 \quad(.0064)$

$.0051 \quad(.0151)$

$.0555 \quad(.0429)$

$.1006 \quad(.1012)$

$.0385 \quad(.0362)$

$.2246 \quad(.0844)$

$.3000 \quad(.1023)$

$.4884 \quad(.2556)$

$-.6464 \quad(.2403)$

$-1.3149 \quad(.4281)$

$b_{1}$

$b_{2}$

.412

.118

.058

.049

.012

.000

.635

.557

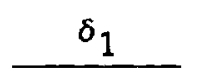

$\delta_{2}$

.412

.118

.058

.049

.012

.000

.635

.557 
Appendix Table 7. Parameter estimates with $b_{1}$ and $b_{2}$ parameterized, $s=s_{2}$, additive disturbance

\begin{tabular}{|c|c|c|c|c|}
\hline Variable & Estimate & te (Asymptotic & Standard Error) & \\
\hline \multicolumn{5}{|l|}{ Origin Parameters: } \\
\hline Mean of $a_{1}$ & & 15.43 & $(2.05)$ & \\
\hline Mean of $a_{2}$ & & 3.17 & $(.58)$ & \\
\hline S.D. of $a_{1}$ & & -- & & \\
\hline S.D. of $a_{2}$ & & -- & & \\
\hline Correlation of $a_{1}, a_{2}$ & & -- & & \\
\hline S.D. of $s_{1}$ (at mean) & & 6.75 & $(.62)$ & \\
\hline S.D. of $S_{2}$ (at mean) & & 6.75 & $(--)$ & \\
\hline Correlation of $s_{1}, s_{2}$ & & .15 & $(.06)$ & \\
\hline Determinants of $b_{1}$ and $b_{2}$ : & $b_{1}$ & & $\mathrm{~b}_{2}$ & \\
\hline Income $\left(\$ 1000^{\prime} s\right)$ & -.00510 & $(.00079)$ & -.01225 & $(.0028)$ \\
\hline Age (years) & .0113 & $(.0019)$ & -.0011 & $(.0053)$ \\
\hline Total wealth (\$1000's) & -- & & -- & \\
\hline Non-1 iquid & -.00022 & $(.00011)$ & -.00023 & $(.00059)$ \\
\hline Liquid & .00144 & $(.00051)$ & .0155 & $(.0040)$ \\
\hline Private pension $(0,1)$ & -.0156 & $(.0410)$ & 1.0942 & $(.4482)$ \\
\hline Education (years) & .0292 & $(.0082)$ & .0444 & $(.0269)$ \\
\hline Unmarried woman & .0380 & $(.0655)$ & .1013 & $(.1837)$ \\
\hline Unmarried man & .0466 & $(.0522)$ & .3632 & $(.1311)$ \\
\hline Constant & -1.653 & $(.216)$ & -2.768 & $(.770)$ \\
\hline Predicted $b_{1}$ and $b_{2}:$ & $\mathrm{b}_{1}$ & & $\mathrm{~b}_{2}$ & \\
\hline Mean & .169 & & .078 & \\
\hline S.D. & .036 & & .074 & \\
\hline Min & .011 & & .000 & \\
\hline $\operatorname{Max}$ & .318 & & .933 & \\
\hline Predicted $\delta_{1}$ and $\delta_{2}$ & $\delta_{1}$ & & $\delta_{2}$ & \\
\hline Mean & .240 & & .078 & \\
\hline Standard deviation & .162 & & .074 & \\
\hline Min & .011 & & .000 & \\
\hline $\operatorname{Max}$ & 4.427 & & .933 & \\
\hline LF & & -1377 & & \\
\hline
\end{tabular}


Appendix Table 8. Simulated predicted vs actual values, by income interval, $b_{1}$ and $b_{2}$ parameterized. ${ }^{a}$

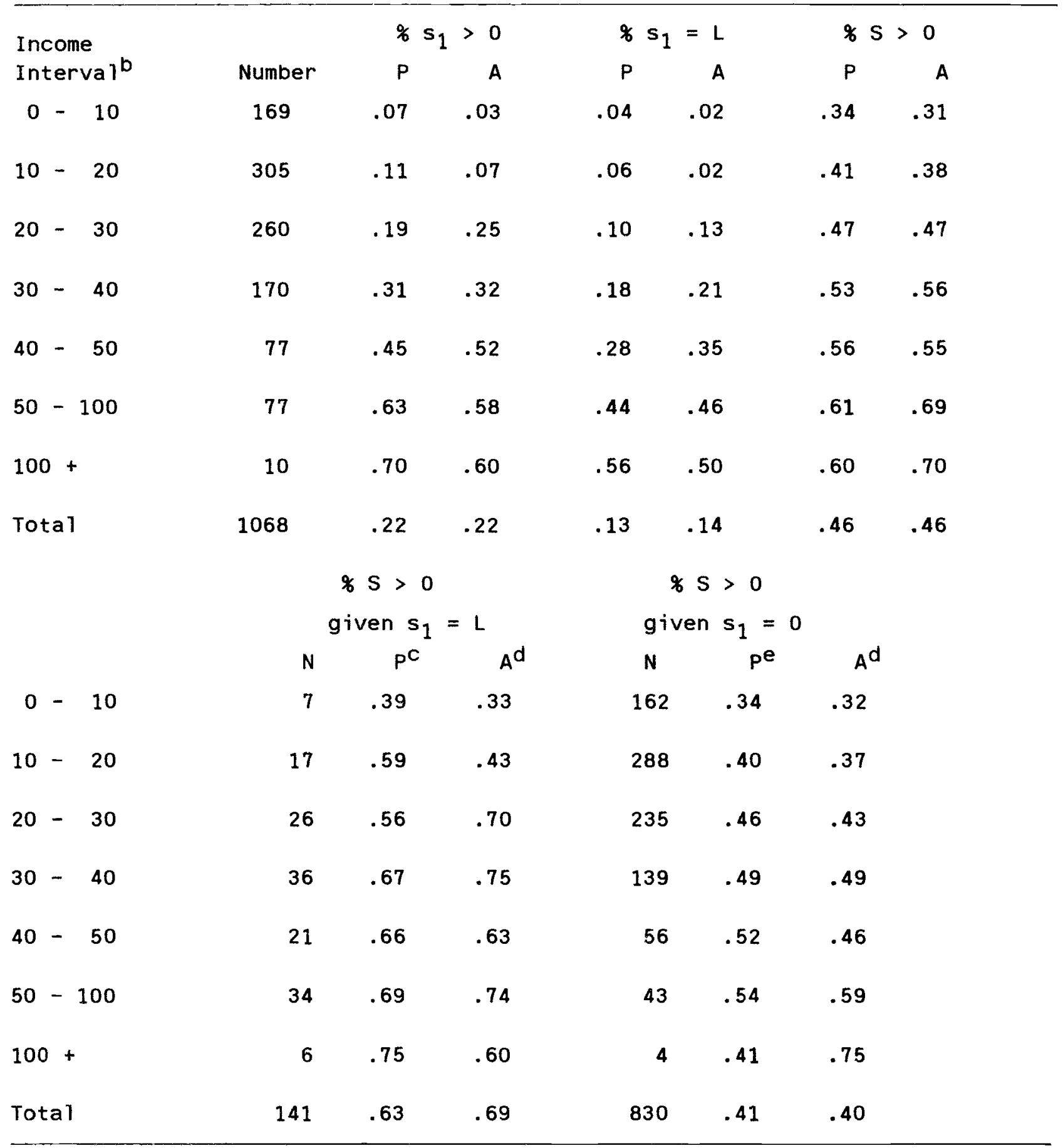

a. Based on 10 draws per sample observation, and on the parameter estimates in text table 7 .

b. $\quad Y-T$, in thousands of dollars.

c. Predicted $S>0$, given predicted $S_{1}=L$.

d. Observed in the sample.

e. Predicted $S>0$, given predicted $S_{1}<0$. 


\section{References}

Bernheim, B. Douglas. 1984. "Dissaving After Retirement: Testing the Pure Life Cycle Hypothesis," NBER Working Paper No. 1409, July.

Blackorby, Charles, Richard Boyce, and R. Robert Russell. 1978. "Estimation of Demand Systems Generated by the Gorman Polar Form; A Generalization of the S-Branch Utility Tree." Econometrica, Vol. 46, No. 2, March, p. 345-363.

Brown, Murray and Dale Heien. 1972. "The S-Branch Utility Tree: A Generalization of the Linear Expenditure System." Econometrica, Vol. 40, No. 4 , July, p. 737-747.

Calvo, G.A. 1979. "On Models of Money and Perfect Foresight," International Economic Review 20, pp. 83-103.

Deaton, Angus. 1981. "Theoretical and Empirical Approaches to Consumer Demand Under Rationing." in A. Deaton, Essays in the Theory and Measurement of Consumer Behavior, Cambridge University Press.

Deaton, Angus and John Muellbauer. 1981. "Functional Forms for Labor Supply and Commodity Demands With and Without Quantity Constraints."

Econometrica, Vol. 49, No. 6, November, p. 1521-1532.

Diamond, Peter and Jerry Hausman. 1984. "Individual Retirement and Savings Behavior." Journal of Public Economics. Vol. 23, June, p. 81-114. 
Fischer, Stanley. 1979. "Capital Accumulation on the Transition Path in a Monetary Optimizing Economy," Econometrica 47, pp. 1433-1439.

Griliches, Zvi and Vidar Ringstad. 1971. Economies of Scale and the Form of the Production Function. North-Holland.

Hausman, Jerry and Paul Ruud. 1984. "Family Labor Supply with Taxes," American Economic Review, Vo1. 74, No. 2, May, p. 242-248.

Hurd, Michael and John Shoven. 1985. "The Distributional Impact of Social Security." in 0. Wise (ed.), Pensions, Labor, and Individual Choice, University of Chicago Press.

King, Mervyn A. 1985. "The Economics of Saving: A Survey of Recent Contributions." in K. Arrow and S. Honkapohja (eds), Frontiers of Economics, Basil Blackwe11.

King, Mervyn A. and Jonathan I. Leape. 1984. "Wealth and Portfolio Composition: Theory and Evidence." National Bureau of Economic Research Working Paper No. 1468, September.

Mundlak, Yair. 1975. "Production Functions - A Survey of Some Open Problems," manuscript.

Obstfeld, Maurice. 1984. "Multiple Stable Equilibria in an Optimizing Perfect-Foresight Mode1," Econometrica 52, pp. 223-228.

Obstfeld, Maurice. 1985. "The Capital Inflows Problem Revisited: A Stylized Model of Southern Cone Disinflation," Review of Economic Studies 52, pp. 605-624. 
Poterba, James M. and Julio J. Rotemberg. 1986. "Money in the Utility Function: An Empirical Implementation," Massachusetts Institute of Technology Working Paper No. 408, January.

U.S. President. 1985. The President's Tax Proposals to the Congress for Fairness, Growth, and Simplicity. USGPO, May.

U.S. Department of Treasury. 1984. Tax Reform for Fairness, Simplicity, and Economic Growth. USGPO.

Venti, Steven F, and David A. Wise, 1985a. "The Determinants of IRA Contributions and the Effect of Limit Changes." National Bureau of Economic Research Working Paper No. 1731, October.

Venti, Steven F. and David A. Wise. 1985b. "Tax-Deferred Accounts, Constrained Choice, and Estimation of Individual Saving." Forthcoming in Review of Economic Studies.

Wise, David A. 1985. "Contributors and Contributions to Registered Retirement Savings Plans." Prepared for the Tax Policy and Legislation Branch of the Canadian Department of Finance, April, 1985 manuscript.

Wise, David A. 1984. "The Effects of Policy Changes on RRSP Contribution." Prepared for the Tax Policy and Legislation Branch of the Canadian Department of Finance, March 1984 manuscript. 